\title{
Heat Engine Regenerators: Research Status and Needs
}

R. A. Hutchinson

August 1987

Prepared for the U.S. Department of Energy under Contract DE-AC06-76RLO 1830

Pacific Northwest Laboratory Operated for the U.S. Department of Energy by Battelle Memorial Institute 


\title{
DISCLAIMER
}

This report was prepared as an account of work sponsored by an agency of the United States Government. Neither the United States Government nor any agency thereof, nor Battelle Memorial Institute, nor any of their employees, makes any warranty, expressed or implied, or assumes any legal liability or responsibility for the accuracy, completeness, or usefulness of any information, apparatus, product, or process disclosed, or represents that its use would not infringe privately owned rights. Reference herein to any specific commercial product, process, or service by trade name, trademark, manufacturer, or otherwise, does not necessarily constitute or imply its endorsement, recommendation, or favoring by the United States Government of any agency thereof, or Battelle Memorial Institute. The views and opinions of authors expressed herein do not necessarly state or reflect those of the United States Government or any agency thereof, or Battelle Memorial Institute.

\author{
PACIFIC NORTHWEST LABORATORY \\ operated by \\ BATTELLE MEMORIAL INSTITUTE \\ for the \\ UNITED STATES DEPARTMENT OF ENERGY \\ under Contract DE-AC06-76RLO 1830
}

\begin{tabular}{|c|c|}
\hline \multicolumn{2}{|c|}{ Printed in the United States of America } \\
\hline \multicolumn{2}{|c|}{ Available from } \\
\hline \multicolumn{2}{|c|}{$\begin{array}{l}\text { National Technical Information Service } \\
\text { United States Department of Commerce }\end{array}$} \\
\hline \multicolumn{2}{|c|}{5285 Port Royal Road } \\
\hline \multicolumn{2}{|c|}{ Springfield, Virginia 22161} \\
\hline \multirow{2}{*}{\multicolumn{2}{|c|}{$\begin{array}{l}\text { NTIS Price Codes } \\
\text { Microfiche A01 }\end{array}$}} \\
\hline & \\
\hline \multicolumn{2}{|c|}{ Printed Copy } \\
\hline & Price \\
\hline Pages & Codes \\
\hline $001-025$ & $\mathrm{~A} 02$ \\
\hline $026-050$ & $\mathrm{~A} 03$ \\
\hline $051-075$ & $\mathrm{~A} 04$ \\
\hline $076-100$ & A05 \\
\hline $101-125$ & AD6 \\
\hline $126-150$ & A07 \\
\hline $151-175$ & $A 0 B$ \\
\hline $176-200$ & $A 09$ \\
\hline $201-225$ & $A 010$ \\
\hline $226-250$ & A011 \\
\hline $251-275$ & $\mathrm{~A} 012$ \\
\hline $276-300$ & $A 013$ \\
\hline
\end{tabular}


HEAT ENGINE REGENERATORS:

RESEARCH STATUS ANO NEEDS

R. A. Hutchinson

August 1987

Prepared for

the U.S. Department of Energy

under Contract DE-AC06-76RLO 1830

Pacific Northwest Laboratory

Richland, Washington 99352 


\section{ABSTRACT}

The rapidly oscillating, variable density flows of regenerative heat engines provide a class of poorly understood unsteady flow and heat transfer problems. These problems are not currently amenable to direct experimental resolution. Experiences in engine development and test programs and efforts to develop analysis tools point to the regenerator as a key area of insufficient understanding. Focusing on flow and heat transfer in regenerators, this report discusses similarity parameters for the flows and reviews the experimental data currently available for Stirling analysis. Then a number of experimental results are presented from recent fundamental fluid mechanical and thermal investigations that shed additional light on the functioning of heat engine regenerators. Suggestions are made for approaches for further measurement and analysis efforts. 


\section{SUMMARY}

The performance of a regenerator is not readily separable from the performance of the remainder of the heat transfer/thermodynamic/gasdynamic system that is an advanced closed-cycle heat engine. Despite the difficulty, this report focuses as closely as possible on the regenerator. Regenerators play an extremely important role in high-efficiency closed cycles, yet knowledge of regenerators and ability to design them is very limited. Even the most complex analysis codes available are not particularly reliable in work on new, substantially different machines. Various kinds of regenerator problems in recent engine development efforts in Japan, at General Electric, and at Mechanical Technology, Inc, have demonstrated some of the difficulties in designing such machines. The inexplicability of engine tests run with different regenerators (to determine which give better performance) provides further evidence. In this report, the physics of regenerator behavior are discussed to illuminate where current data and assumptions are faulty and why understanding is so limited.

The physics governing regenerator behavior is described by a set of fluid equations (equation of state, mass, momentum and energy) coupled with an energy equation for the solid matrix. The fluid equations, complete three-dimensional equations for time-dependent, variable density flow, cannot be solved for regenerator geometries with current computer capacity. A preferred alternative for analyzing such problems is to use dimensional analysis, which can yield governing parameters (called similarity parameters) without solving the equations. Development of similarity parameters for regenerators shows that dynamic and geometric similarity between regenerator experiments and Stirling and other heat engine flows has not been attained. Several key parameters-kinetic Reynolds number, Eckert number, and as yet unspecified geometrical parameters-were not considered in experimental work. Although in limited cases they may be unimportant, ignoring these parameters has typically been based on assumption rather than on analysis. Geometrical parameters, which come from boundary conditions (which are just as much part of the problem being solved as the equation is), are handled particularly poorly. Even the basis for defining length scales for more conventional parameters such as Reynolds 
number is not established. It is apparent that shortcomings in understanding and analysis of regenerators are in part due to dependence on inappropriate experimental results.

Closer examination of steady flow data currently used in heat engine regenerator analysis shows why similarity has seldom been considered. The key data (Kays and London 1984) used were gathered 20-40 years ago for an entirely different application (gas turbines), and the parameters used for correlations and the experimental techniques developed were based on the requirements and the expected analysis methodology for that application. Unfortunately the requirements and analysis methods for heat engines are not the same as for gas turbines. Instead, assumptions have been made in order to use the data anyway, as for many years it was the only information available. In particular, the quasi-steady assumption used to substitute steady flow data for instantaneous data within the oscillating flow may be suspect, even though arguments in favor of its use for regenerators are still made. In situations where kinetic Reynolds number and other previously-ignored similarity parameters are very sma11, these arguments are reasonable. But for the general case, indeed, in every case until analysis has determined the relative magnitudes of governing parameters, ignoring parameters means ignoring important physics.

Some attention has been paid to the shortcomings of steady-flow, gasturbine-based data. But very little oscillating flaw work has been done for regenerators because test-oriented experiments are almost as difficult as building a working heat engine and instrumenting it. In addition, reported results have not reached conditions at all similar to working engines, and experimental rigs are not sufficiently well instrumented to provide detailed, fundamental information about the flows they are able to create. These testoriented experiments were designed to be realistic, yet practical, and have had only limited success. Improving instrumentation of working engines, as has been done in Japan, may be equally practical for getting this type of "component test" results.

In addition, the fundamental understanding that this type of work cannot provide must be sought elsewhere, with simplified, fluid mechanical experiments, perhaps in situations where flow visualization and detailed measurements 
are possible. Fortunately, some of the phenomena that cannot be probed by current realistic experiments have already received initial attention in fundamental studies driven by Stirling and IC engines, cryogenics, chemical reactor design, or other applications. These include heat transfer during compression or expansion (cyclic heat transfer); enhanced axial thermal diffusivity in oscillating laminar flows; effective formulations for treating porous media that permit treatment of special effects such as nonuniform porosities or nonuniform regenerator design; and heat transfer enhancement in oscillating flow in porous media.

This report presents observations and scoping calculations on what these recent fundamental results may mean for heat engine regenerators, based on study of the original research and knowledge of the heat engine regenerator application. Because no detailed analysis has been done, however, these observations are little more than informed speculation. The major limitation to doing detailed analysis is knowledge of the kind of flows present in a regenerator, which affect choices of hydraulic diameters, thermal diffusivities, and other key parameters. Improved knowledge of regenerator flows must be addressed by experiments, utilizing visualization or other means of getting detailed data.

Experiments undertaken from a narrow perspective will not succeed by themselves, however. It is clear both from the examination of flow and heat transfer data and from the review of fundamental research in this report that the topic of heat engine regenerators is a classic "between disciplines" problem. It demands several types of expertise: fluid mechanics (detailed analysis of flow effects), heat transfer (convection and conduction), chemical engineering (porous media), heat engines (the problem "framework" and end goal), and possibly, acoustics (pressure measurement expertise). A great deal of cooperation between disciplines that do not typically interact will be needed.

A second need for cooperation and coordination is between experimental work and analysis. Data must be taken in such a way that they are readily usable, without additional error, in an analysis. Stated another way, analysis must be formulated in such a way that it can use available data without inducing additional errors. In this area, where rapidly-time-varying, 
high-pressure, high-temperature flows (dominated by nonlinear problems) are being treated, both experimentalists and analysts have their hands full. Current treatments are very limited, and even the assumptions made, explicitiy or implicitly, are not recognized. The researchers must work together on tasks such as working out schemes to avoid either quasi-steady flow assumptions or perfect instantaneous measurement assumptions. Only then will a scientifically verified regenerator design capability be available for development of highefficiency machines. 


\section{ACKNOWLEDGMENTS}

The author would like to thank Marvin Gunn, program manager of the Energy Conversion and Utilization Technologies Program of the U.S. Department of Energy, for his longstanding interest in and support for this review. In addition, comments and insights from David Gedeon, Gary Wood, Joe Smith, Jr., Al Kornhauser, Paul Roach, Joerg Seume, Terry Simon, and Alan Organ are warmly appreciated. All statements and any errors are the responsibility of the author alone, however. 


\section{CONTENTS}

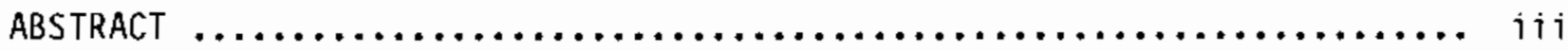

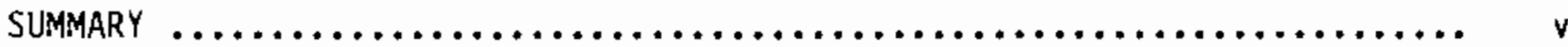

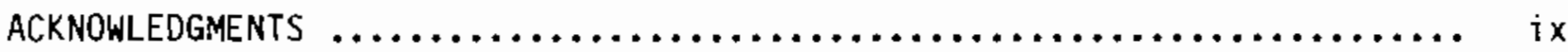

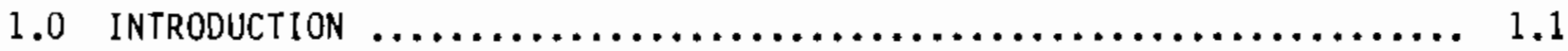

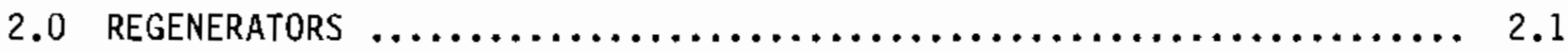

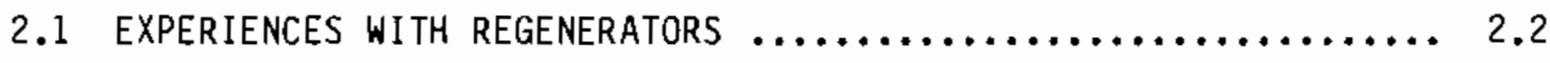

2.1.1 Engine Tests $\ldots \ldots \ldots \ldots \ldots \ldots \ldots \ldots \ldots \ldots \ldots \ldots \ldots \ldots, 2.2$

2.1 .2 Regenerator Analysis $\ldots \ldots \ldots \ldots \ldots \ldots \ldots \ldots \ldots \ldots \ldots \ldots \ldots \ldots \ldots \ldots, 2.5$

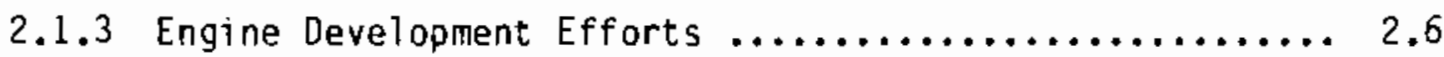

2.2 ROLE OF RESULTS FROM OTHER FIELDS $\ldots \ldots \ldots \ldots \ldots \ldots \ldots \ldots \ldots \ldots, 2.7$

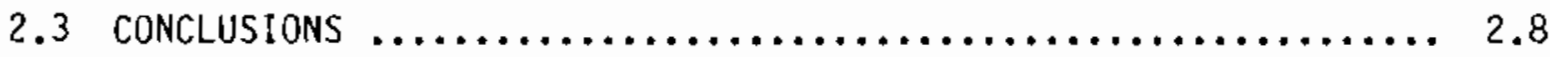

3.0 Flows in CURRENT HEAT Engine Regenerators $\ldots \ldots \ldots \ldots \ldots \ldots \ldots \ldots \ldots, 3.1$

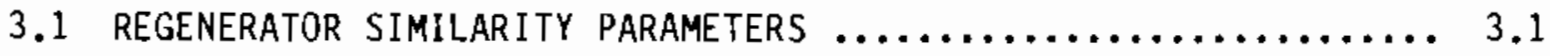

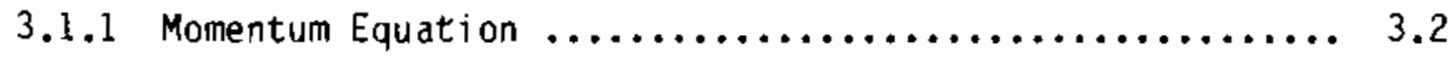

3.1 .2 Energy Equation $\ldots \ldots \ldots \ldots \ldots \ldots \ldots \ldots \ldots \ldots \ldots \ldots \ldots \ldots \ldots \ldots \ldots \ldots, 4$

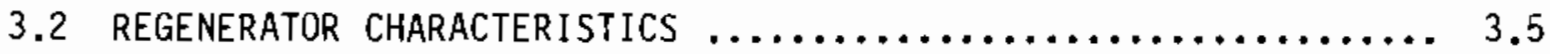

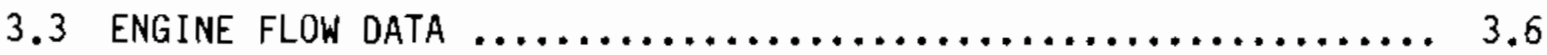

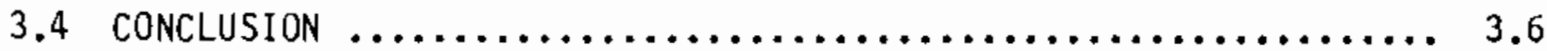

4.0 EXISTING DATA ON FRICTION AND HEAT TRANSFER $\ldots \ldots \ldots \ldots \ldots \ldots \ldots \ldots, 4.1$

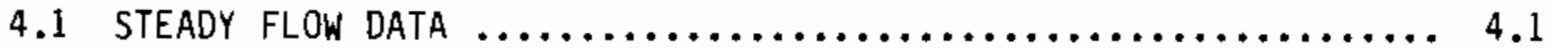

4.1 .1 Non-Darcy Flow $\ldots \ldots \ldots \ldots \ldots \ldots \ldots \ldots \ldots \ldots \ldots, 4.2$

4.1.2 Geometric Parameterization ..................... 4.2

4.1.3 Experimental Difficulty $\ldots \ldots \ldots \ldots \ldots \ldots \ldots \ldots \ldots \ldots \ldots \ldots \ldots \ldots, 4.3$

4.1.4 Quasi-Steady Assumptions $\ldots \ldots \ldots \ldots \ldots \ldots \ldots \ldots \ldots \ldots, 4.4$ 
4.1 .5 Steady Flow Summary $\ldots \ldots \ldots \ldots \ldots \ldots \ldots \ldots \ldots \ldots \ldots, 4.4$

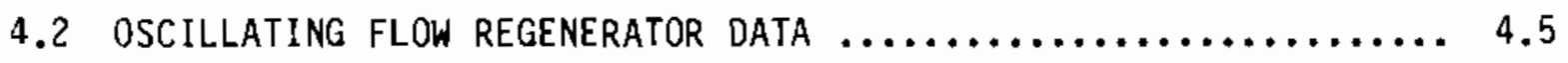

4.2.1 Experimental Problems ........................... 4.6

4.2 .2 Simplifications Used $\ldots \ldots \ldots \ldots \ldots \ldots \ldots \ldots \ldots \ldots \ldots \ldots \ldots \ldots \ldots, 4.9$

4.2.3 Regenerator Testing Approach ...................... 4.10

4.2.4 Data Analysis ................................. 4.10

4.2 .5 0scillating Flow Summary .......................... 4.11

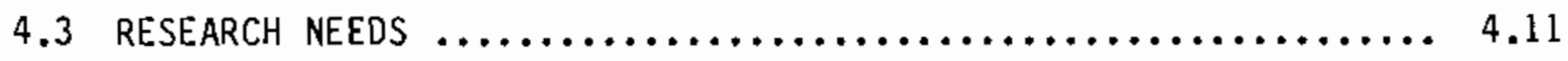

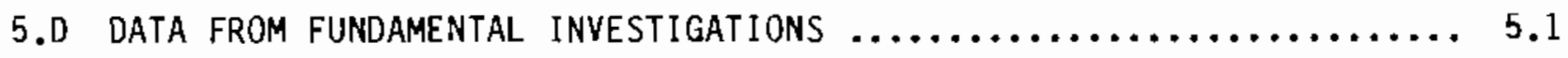

5.1 heAT tRANSFER DURING COMPRESSION AND EXPANSION ............. 5.1

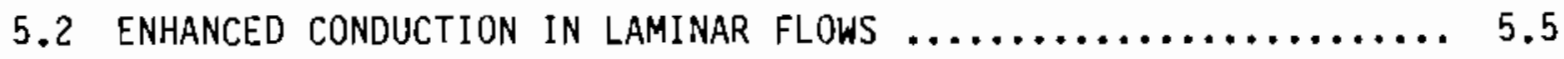

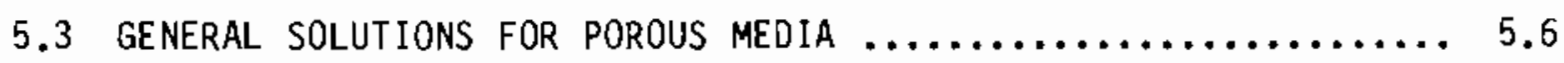

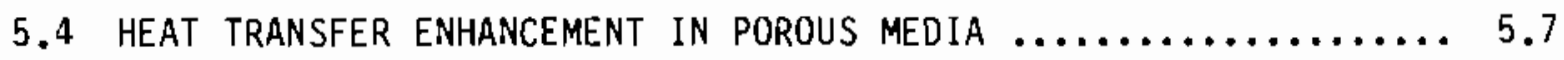

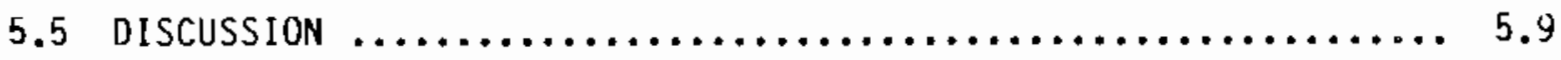

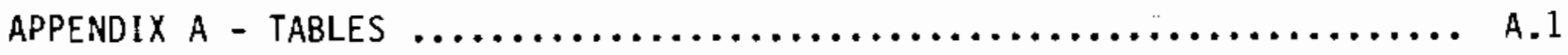

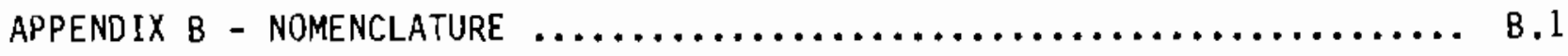

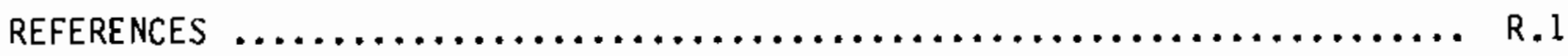




\section{FIGURES}

2.1 Conceptual Diagram of Stirling Cycle $\ldots \ldots \ldots \ldots \ldots \ldots \ldots \ldots \ldots \ldots, 2.1$

2.2 Regenerator Test: Summary of Regenerator Porosity Effect on

Power and Efficiency....................................... 2.3

3.1 Reynolds Number Versus Dimensionless Frequency $\ldots \ldots \ldots \ldots \ldots \ldots \ldots . .7$

3.2 Relative Amplitude of Fluid Motion Versus Dimensionless

Frequency $\ldots \ldots \ldots \ldots \ldots \ldots \ldots \ldots \ldots \ldots \ldots \ldots \ldots \ldots \ldots \ldots \ldots \ldots \ldots \ldots, 3.7$

4.1 Experimental Results Within Stirling Regenerator Flow Regime ...... 4.6

4.2 Schematic Diagram of Reading Test Section $\ldots \ldots \ldots \ldots \ldots \ldots \ldots \ldots . . \ldots \ldots$

4.3 Schematic Diagram of Argonne Test Section ................... 4.8

5.1 Compression/Expansion Heat Transfer Characteristics $\ldots \ldots \ldots \ldots \ldots .6 .2$

5.2 Heat Transfer Losses In Compression/Expansion $\ldots \ldots \ldots \ldots \ldots \ldots \ldots . . . \ldots$

5.3 Heat Transfer Enhancement Due to Oscillating Flow in Porous

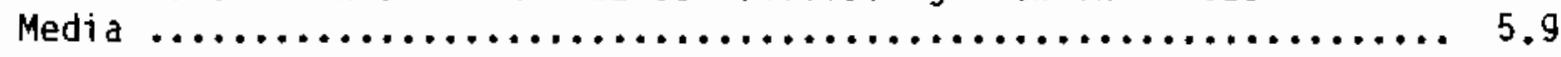




\subsection{INTROOUCTION}

In recent years several hundred million dolliars have been spent in the United States and overseas on development of new closed cycle heat engines, including prime movers, refrigerators and heat pumps, because of their many promising operating characteristics: high efficiency, low noise, fuel flexibility, convenient operating temperatures, and long life.

These machines involve new kinds of unsteady internal flows not prevalent in other applications. Up to this time, however, the characteristics of these flows have not been fully investigated and methods to analyze them have not been developed. Instead, simplified component tests are the cornerstones of current heat engine analysis. Though many analysis codes based on such tests have been used to predict the performance of actual engines, the varying and unspecifiable accuracy of current analysis has limited the development of new machines.

In fact, the design of a new high-performance heat engine has proved to be quite risky. Although projects have been terminated for a wide variety of reasons, much of the work has been compounded by its technical difficulty. In the Stirling technology area, for instance, numerous designs have not performed as expected. These included new engine designs by firms with long Stirling traditions as well as firms new to the technology. Unfortunately detailed evidence about these efforts is not readily gathered and remains largely anecdotal.

The difficulty with heat engine development projects has several aspects. Because heat engines function as complex, interactive thermal systems, they can require considerable redesign and rebuild when thermal design errors are made. In addition, the analysis code results and experiments with both successful and

unsuccessful engines have seldom directly pinpointed key sources of error. The frequency with which thermal or pressure drop problems are encountered, however, suggests that part of the blame does lie on the initial flow and heat transfer experimental data on which the codes are based, or on assumptions implicit in their use. 
It is difficult to explicitly demonstrate the extent to which improved understanding would ease heat engine development problems, however. Some engines, because of their operating conditions, have not had the difficulties that others have had. High-efficiency engines, though, have virtually all been problematical. These machines depend strongly on excellent heat exchanger performance, particularly that of the regenerator.

The regenerator is still an enigma to heat engine analysts. Pressure drop multipliers (to increase calculated pressure drop beyond the level expected based on simple test rigs), for instance, have been necessary for regenerator analysis in Stirling design codes for many years (Martini 1983; Chen and Griffin 1983). Such adjustments may still not reflect regenerator performance with any accuracy, but rather may correct for errors in other component models or in assumptions about how the heat engine system works. Thus a careful review of current knowledge of regenerators, focusing particularly on present experimental knowledge and future measurement needs, is an important priority in heat engine development. This report provides such a review. For clarity and because of the wide availability of data on their design and performance, Stirling applications are typically taken as an example. The discussion is equally applicable to a variety of other regenerative (Ericcson, Villemevier, etc.) cycles, and may also give insight into unsteady heat transfer and flow in other heat engines, pulse combustors, and other applications.

Chapter 2.0 of this report outlines the experiences in engine development and test programs, as well as with development of analysis tools, that identify the regenerator as an area of insufficient understanding. Focusing on flow and heat transfer in regenerators, Chapter 3.0 then discusses the fundamental equation set for the flows and derives similarity parameters for them. Chapter 4.0 reviews the limited experimental data currently available for heat engine analysis, and outlines problems with that data. Then in Chapter 5.0, a number of experimental results from recent fundamental fluid mechanical and thermal investigations that shed additional light on the functioning of regenerators are presented. General recommendations for further work are given. 


\subsection{REGENERATORS}

This chapter outlines the basic operation of heat engine regenerators, using the example of Stirling engines. It discusses the current practical knowledge about how regenerators have worked in experiments, analysis and in recent engine development efforts. It shows the importance of regenerators to heat engines, and gives evidence on the degree to which they are not understood. More detailed discussion on shortcomings in current understanding is in further chapters.

In a Stirling engine, medium-to high-pressure gas flows through three heat exchangers (cooler, regenerator and heater) located between an expansion space cylinder and a compression space cylinder (Figure 2.1). The pistons in the cylinders control (or are controlled by) the thermodynamics occurring in the

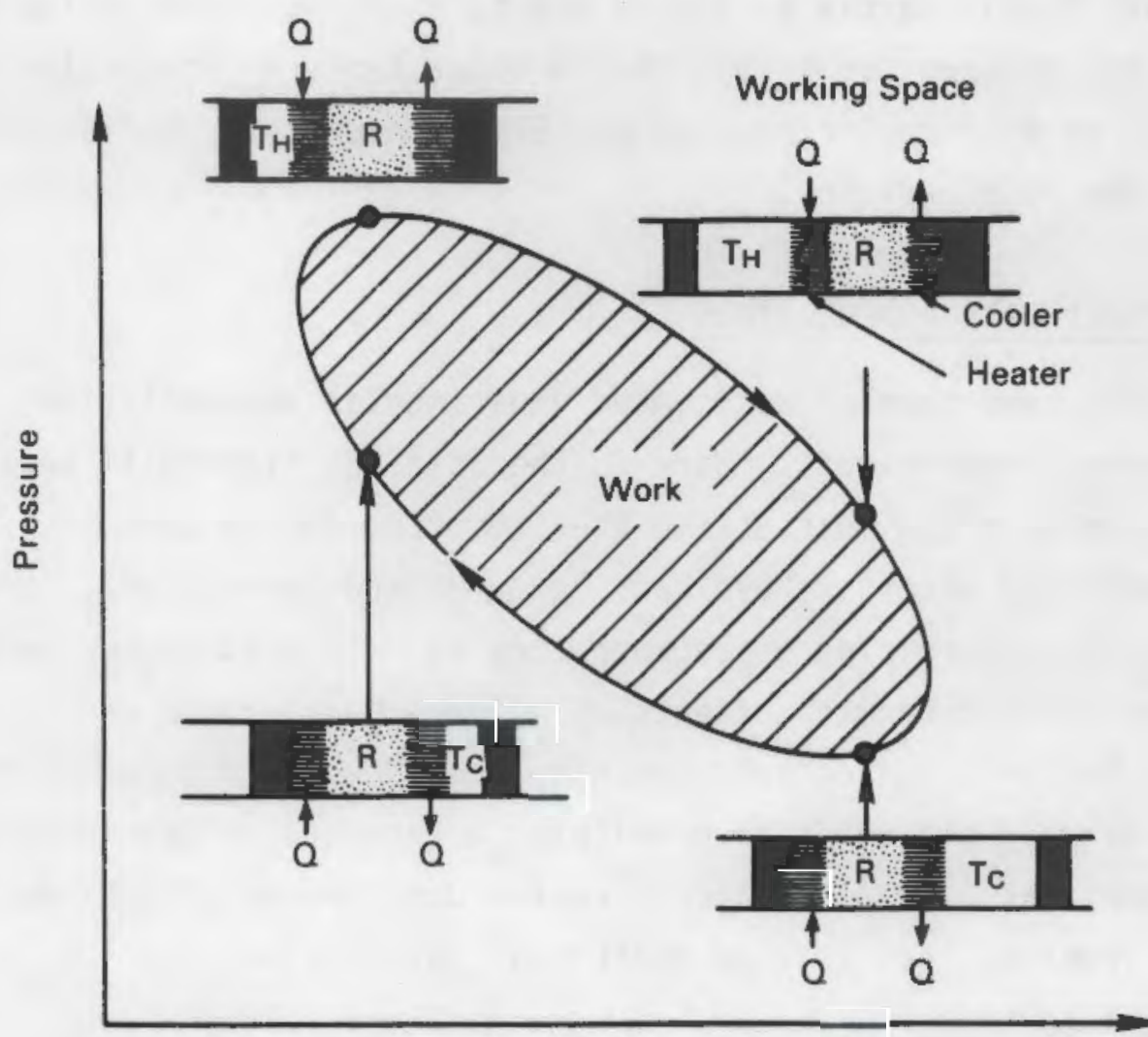

Volume

FIGURE 2.1. Conceptual Diagram of Stirling Cycle (Martini 1983) 
system. The flow geometries can be complex, and the overall volume available for the working gas varies as the engine produces work. The flow moves rapidly back and forth along short paths within the heat exchangers or into and out of the working spaces.

The regenerator in high-efficiency engines is typically a packed stack of wire screens or a sintered wire matrix. Machines for use in low-temperature regimes often use different regenerator materials, such as packed beds of lead, because of significant differences in specific heats in the cryogenic regime compared with higher temperatures. The heater and cooler usually have more conventional tubular geometries, though connecting passages and other spaces may be quite complex. The regenerator may transfer an order of magnitude more heat than the other exchangers and may account for a large part of the overall pressure drop in some Stirling machines (Urieli and Berchowitz 1984). Thus it can contribute significantly to losses and to analytical and design errors. The role of the regenerator is similar in other types of innovative heat engines, such as Villemeuier heat pumps, Ericcson engines, and several types of low temperature refrigerators.

\subsection{EXPERIENCES WITH REGENERATORS}

There have been several documented experimental and analytical efforts to learn more about regenerators. Work in the Stirling field will be treated here, as it has been the most active area reported in the open literature. At least two published efforts (Moynihan, Berggren and Dochat 1983; Barnes and Reader 1986) include testing of regenerators in well-established working Stirling engines to determine effects of different materials and regenerator parameters. Design-oriented analyses have been developed that can focus more closely on the many tradeoffs in developing a regenerator than complex numerical codes can. Finally, recent engine development efforts have had regenerator problems that provide additional perspective.

\subsubsection{Engine Tests}

Tests of regenerators in working engines do not show any clear, generalizable causality between any tested regenerator attribute and changes in engine performance. Moynihan, Berggren and Dochat (1983) undertook a set of tests of 
knitted mesh regenerators on a 1-kW, medium-speed $(45 \mathrm{~Hz})$, medium-pressure $(4.0 \mathrm{MPa})$ free-piston engine and compared the results with their engine simulation. Engine power decreased as mesh porosity increased above $70 \%$ (Figure 2.2). This was partly because of an increase in dead volume (working gas within the regenerator that does not contribute to production of work), but mostly because of a reduction in the pressure phase angle (the key indicator for power production) of the compression space. How the increases in regenerator porosity caused this change in pressure phasing was not determined.

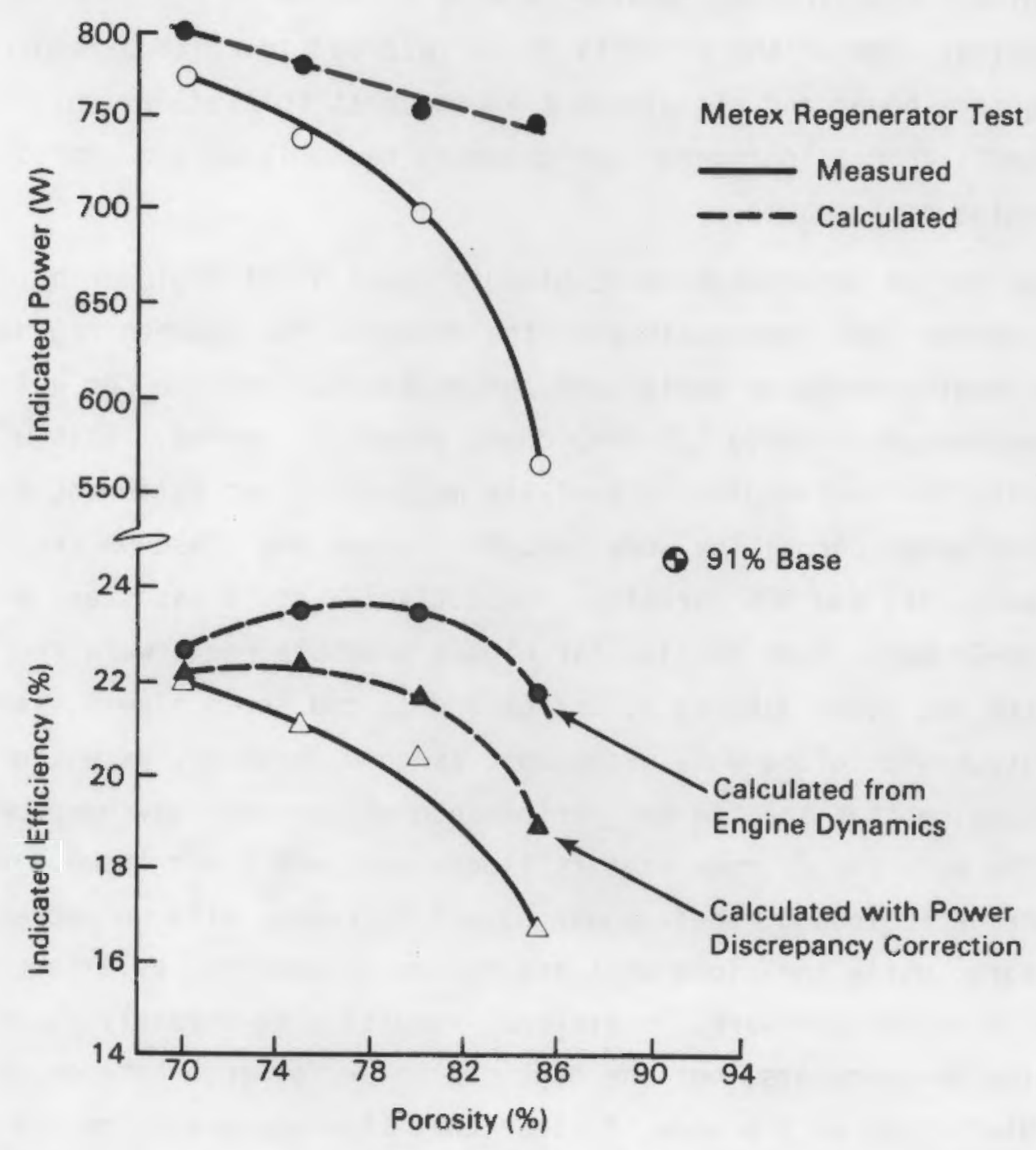

FIGURE 2.2. Regenerator Test: Summary of Regenerator Porosity Effect on Power and Efficiency (Moynihan, Berggren and Dochat 1983) 
Parameters thought to set this phase angle were all measured or presumed to be nearly constant except the heat exchanger pumping power (power used to overcome pressure drop).

The pressure drop in the regenerators is therefore a key unknown, although from Moynihan's work it is difficult to say how it changed engine power production. The analysis code used did not reproduce either power or efficiency results, though it used pressure drop and heat transfer correlations that were accurate for the tested regenerators in steady flow. A further anomaly was that the engine's standard regenerator, a wire screen with $91 \%$ porosity rather than mesh design, opposed the porosity trend recorded in knitted-mesh results by producing more power and efficiency than the best knitted design. Thus a relatively small change in regenerator geometry had a large and unpredictable effect on engine performance.

A second set of experiments at England's Royal Naval Engineering College (Barnes and Reader 1986) has dealt with the relationship between regenerator performance, engine pressure variations and engine performance for a low-speed $(20 \mathrm{~Hz})$, low-pressure (0.4 to $1.5 \mathrm{MPa})$ crank drive air engine. This work aimed to provide data for semi-empirical analysis methods. Four different regenerators with different porosities were tested: 1oose- and close-packed stainless steel wire wool, $91 \%$ and $80 \%$ porosity, respectively; stainless steel wire mesh (59\%); and $\mathrm{Ni}-\mathrm{Cr}$ metal foam (87\%). Far higher pressure peaks were reached with mesh than with the other materials, indicating it had fewer flow losses. Overall power output with close wool was almost as good, however, as was efficiency, indicating that the thermal performance of the wool may have been superior. The more porous regenerators (loose wool and $\mathrm{Ni}-\mathrm{Cr}$ foam) had much poorer performance; indeed, their power output decreased with an increase in engine pressure, while the close wool and mesh regenerators, as expected, did better with increased pressure. Efficiency results also strongly favored the lower porosity regenerators, but the huge gap in performance between close wool at $80 \%$ and $\mathrm{Ni}-\mathrm{Cr}$ foam at $87 \%$ made it clear that the regenerator matrix geometry is at least as important as porosity or mass. 


\subsubsection{Regenerator Analysis}

Researchers attempting to improve regenerator design have proposed a number of simple calculation procedures that do not require large amounts of computer time. These efforts seek to focus on specific tradeoffs in regenerator design in far more explicit ways than are possible with numerical solutions of the one-dimensional equations for the working fluid. One effort (Jones 1982a) emphasized the importance of the ratio between regenerator matrix and working gas specific heats, which is a factor limiting regenerator performance. Another (Miyabe, Takahashi and Hamaguchi 1982) also focused on heat capacity, paying special attention to the diameter of the wires and the number of screens in screen regenerators. A third (Lazarides, Rallis and $\mathrm{Kilgour}$ 1984) developed an optimizing procedure based on calculating and minimizing the ratio of energy loss to energy storage using simple models for losses. A fourth (Bartolini and Naso, 1984) used a simplified regenerator model that permitted development of parameterized curves examining the influences on thermal effectiveness of types of working gas, gas temperature range, engine speed, and regenerator mass and dead volume. There are few experimental data to support or disallow any of their results. Three of the four efforts did include experimental work published overseas at Italian and Japanese conferences and in graduate theses (Bartolini 1981; Boletta et al. 1981; Jones 1982b; Hamaguchi, Takahashi and Miyabe 1981a and 1981b), but the work was extremely limited.

- Instead, the primary verification used for the research noted above and in other simplified design approaches is comparison with the results of detailed Stirling cycle simulations. Although they do not focus closely on the regenerator, these simulations do provide a more realistic treatment of overall working gas behavior by solving more complete forms of the basic equations (including mass, momentum and energy equations). As noted in Seume and Simon (1986) and Hutchinson and Lyke (1987), these codes depend very clearly on steady flow friction and heat transfer tests on regenerator materials, and thus (as discussed in Chapter 4.0) cannot be regarded as validated for real engine operating conditions.

Thus "verification" of simple codes with more complex codes is a misnomer and does not necessarily contribute to the understanding of regenerators. 
Rather, it shows how to simply model the same behavior that is predicted, correctly or not, by the complex code, under the circumstance used for the comparison. When used with skill and judgment, complex codes do seem to work well in certain circumstances--those that involve more familiar flow regimes for which experience can assist in the analysis. But they can still be unreliable in new flow regimes or in inexperienced hands. Both simple and complex approaches to regenerator analysis, then, are limited by the same shortcomings in experimental data.

\subsubsection{Engine Development Efforts}

Recent engine development efforts provide anecdotal evidence on the importance of regenerators to heat engines and on shortcomings in regenerator design. The key development efforts are not building variations on current, well-tested engines, but entirely new ones. They include several efforts in Japan by researchers new to Stirling engines; a similar effort by General Electric (GE) on a different type of engine in the United States; and the latest Mechanical Technology Inc. (MTI) space power design, which operates in a new, high-frequency regime. Essentially the same types of basic (steady flow) data have been used by almost all Stirling designers in recent years, so although problems encountered in each application may differ, it is not because each designer's data are individually faulty in distinct ways. Instead, they would have to be collectively faulty. The "newness" of the development efforts mentioned leads to the expectation that any lack of fundamental understanding will be reflected in difficulties in the development process.

Indeed, there were regenerator problems in each development case mentioned above, although not enough detail is publicly available (nor is there adequate understanding) to isolate a particular analysis assumption or data set as the culprit. In a paper reviewing Japanese Stirling engine progress (Mitsuda et al. 1985), three of the four Japanese engines developed were determined to have regenerator design problems: Toshiba's $3 \mathrm{~kW}$ engine had excessive friction, and Mitsubishi's 3-kW design had excessive thermal losses, as did the $30 \mathrm{~kW}$ Tokyo Sanyo machine.

In a case in the U.S. for which details are available, General Electric developed a 3-kW free-piston engine for a Stirling-Rankine heat pump. This 
engine suffered from huge friction losses in the regenerator and cooler, far more than GE's and other codes predicted (General Electric 1984). While the cooler losses, between 6 and 10 times those predicted by various codes, are believed to have been caused by spring insets used to enhance heat transfer, the regenerator losses, between 3 and 7 times those predicted, were not explained. In addition, despite this high pressure drop, regenerator thermal performance (effectiveness) was still far lower than desirable.

Problems have beset firms that are experienced with Stirling engines as well. In developing a large, high-frequency, free-piston engine, MII destroyed a wire mesh regenerator in which the screens were not sintered in place, even though the engine was operating far short of peak pressure and operating speed (Slaby 1986). The ability of a regenerator to destroy itself in a highfrequency machine had not been clear from analysis. With a structurally sound regenerator in place, this machine apparently does perform as expected.

There are, of course, engines for which no particular problems with regenerator operation have occurred. But because the knowledge of operating behavior necessary to satisfactorily design Stirling heat regenerators (and certain other components) is not currently explicit, development progress is sometimes impeded and every advanced heat engine design is a risky project.

\subsection{ROLE OF RESULTS FROM OTHER FIELDS}

Data commonly used to design heat engine heat exchangers originated in applied and basic heat transfer research undertaken for other applications 20 to 40 years ago (Kays and London 1984; Finegold and Sterrett 1978); it has recently been supplemented by data taken by researchers specifically for Stirling and heat engine components (see Table A.l in Appendix A). The recent data have many limitations, partly because they were typically from application-oriented experimental programs and thus did not examine in much detail the physical processes being tested. In the meantime, other applications have resulted in considerable advances in fluid mechanics and heat trans-

fer. Up to this point, heat engine regenerator design has been almost entirely dependent on results developed with other applications in mind. It is important to continue to build on past work, but with a new focus on fundamental 
work, to ensure that heat engine problems are resolved, rather than to accept available data because they are the only data available.

\subsection{CONCLUSIONS}

This chapter outlined practical experience with regenerators in Stirling engines in order to emphasize the importance of regenerators to heat engine performance and to illustrate the extent to which a lack of solid experimental data is limiting the development of such machines. Tests of various regenerators in engines have been unable to provide understanding or good correlations between regenerator characteristics and performance. The effects of regenerator geometry were apparently important but it is not known exactly how.

Regenerator analysis, while often illuminating important issues in regenerator design, is not based on experimental knowledge but rather on agreement with full (3-conservation equation) codes that in themselves are not fully verified. Engine developments using these codes have had mixed success, and in several cases the difficulties in experimental engines have included severe limitations in regenerator performance. The data on which these codes depend were largely developed for applications and may not be suitable for many heat engine applications. Chapter 3.0 discusses the fundamentals of flow in regenerators and introduces the conditions (similarity parameters) that must be met for experimental data to be applicable. 


\subsection{FLOWS IN CURRENT HEAT ENGINE REGENERATORS}

This chapter focuses on basic equations and what can be learned from them about regenerators in current heat engines. The focus is once again on Stirling engines, for which design data and currently used correlations are most readily available. The governing equations for three-dimensional, timevarying flow in a complex geometry like a regenerator cannot be solved with current computational ability. Dimensional analysis, however, is a highly effective means of examining fundamental relationships without solving complex equation sets. It has the added advantage of producing dimensionless numbers (similarity parameters) that can be used to characterize the important physics in the problem being examined. Similarity parameters are not currentiy agreed upon for flows in regenerators; indeed, as will be seen, most of the correlations currently being used for heat engine flows do not include important similarity parameters for such flows.

In this chapter the governing equations for regenerator flows are introduced and similarity parameters for regenerators are developed. Complications introduced by geometry and other boundary conditions and the oscillating, variable density flow phenomena of the Stirling cycle are emphasized. Regenerator characteristics that may prove important are summarized in Table A.1 in Appendix $A$ as a supplementary means (to dimensional analysis) of introducing important regenerator physics. Rough specification (using the derived similarity parameters) of results for flow regimes in regenerators of a number of engines, developed and published by Seume and Simon (1986), are then presented.

\subsection{REGENERATOR SIMILARITY PARAMETERS}

This section determines the important parameters governing regenerator flows by examining the governing equations. The treatment assumes sinusoidal flow oscillation for clarity and because it is, in general, an excellent approximation to many Stirling and other heat engine waveforms. The complications of the complex regenerator geometry are emphasized. From both a 
mathematical and a practical point of view, these initial and boundary conditions are part of the equation and so their contribution to governing parameters is essential too.

\subsubsection{Momentum Equation}

We start with a simplified Navier-Stokes equation; the vector form of the incompressible, variable viscosity momentum equation:

$$
\frac{\partial \vec{u}}{\partial t}+\vec{u} \cdot \nabla \vec{u}=\frac{\nabla P}{p}+v \nabla^{2} \vec{u}
$$

Although the gas flow in heat engines is clearly of varying density, the compressible form of the momentum equation has not been chosen. This is legitimate for engines if the time for the nonsteady flow phenomena to take place in the engine is much longer than the time required for a sound wave to traverse the portion of the flow in which substantial changes of velocity take place (Seume and Simon 1986, Schlichting 1979). This is almost certainly the case in the regenerator, where the distance the wave must travel is very short. Stated another way, the Mach number (which is the additional similarity parameter that would drop out of the compressible equation) for flow in regenerators is very sma 11, so shock phenomena probably do not occur and the compressible momentum equation is not required.

Normalization of Equation (3.1) using the maximum (during the cycle) bulk mean velocity $u_{m, m a x}$, the angular velocity $\omega$ and reference fluid properties $\rho_{0}$ and $v_{0}$ gives the dimensionless equation:

$$
\frac{\operatorname{Re}_{\omega}}{2 \pi} \frac{\partial u^{\star}}{\partial t^{\star}}+\frac{\operatorname{Re} \max }{2} \vec{u}^{\star} \cdot \nabla^{\star} \vec{u}^{\star}=\frac{-\operatorname{Re} \max }{2} \frac{\nabla^{\star} p^{\star}}{0^{\star}}+v^{\star} \nabla^{2 *} \vec{u}^{\star}
$$

Here * signifies a dimensionless property; this result is identical to that obtained in Seume and Simon (1986). Dimensionless frequency $\operatorname{Re}_{\omega}$ (also called kinetic Reynolds number or Valensi number) deals with temporal acceleration, 
and the amplitude Reynolds number, $R e_{\max }$, treats spatial acceleration and pressure gradient terms. Choice of this particular equation as the governing one clearly affects the results of dimensional analysis--note the absence of a Mach number or other term expressing compressibility. The choice of normalizing variables also affects the results; other variable choices are equally possible and equally correct, and in some circumstances, the different resultant parameters might be more functional.

In fact, one very useful parameter for Stirling flows is the amplitude ratio $A_{r}$. An amplitude ratio of less than one means that fluid particles may remain entirely within a given heat exchanger, which, as discussed shortly, limits the assumptions that can be made about their time-variant behavior. The inverse of this parameter was first introduced by Organ (1975); it can be expressed by combining parameters (including, for example, a simple geometrical descriptor, $1 / d$, for a tube geometry) we have already identified:

$$
A_{r}=\frac{1}{2} \frac{d}{1} \frac{R_{\max }}{R e_{\omega}}
$$

A second type of dimensionless parameters must be defined when developing methods to solve regenerator flows in practice. These derive from boundary conditions because, by and large, we are interested in high-efficiency heat engines for which the regenerator geometry is nothing like a simple tube. We can compute only one-dimensional time-varying flows with any efficiency or accuracy (for complex geometries). The geometrical description of regenerators might include a vast number of dimensions, including regenerator length, diameter, porosity, permeability, pore dianeter, wire (mesh) diameter and spacing and packing. These must be combined to form dimensionless numbers describing geometrical similarity, and/or used as length scales in the other similarity parameters, to ensure complete specification of flow physics when comparing different experiments or analyses. Developing appropriate sets of such descriptors is still an important research topic.

A final dimensionless parameter for the momentum equation is the friction factor, which is also a necessary part of a one-dimensional description of 
regenerator flows. It must contain all the information about boundary/fluid interaction. It can be defined, as is standard practice in engineering flows, based on fluid stresses at the wall, although in oscillating flows these gradients vary with time.

\subsubsection{Energy Equation}

A suitable form of the energy equation for heat engine flows is the compressible, variable thermal conductivity form of the energy equation. The compressible equation is used to insure that the energy effects of the flow's variable density are taken into account even though momentum-based compressible effects are probably not important:

$$
\phi+\nabla \cdot(k \nabla T)-\nabla \cdot \vec{q}_{r}=\rho \frac{D e}{D t}+P \nabla \cdot \vec{u}
$$

Normalizing using reference values for specific heat and other gas properties and $\left(T-T_{0}\right) / \Delta T_{0}$ for temperature gives the Prandtl number and the Eckert number as similarity parameters in addition to $\mathrm{Re}_{\omega}$ and $\mathrm{Re}_{\max }$.

The familiar Prandtl number, which depends entirely on gas properties, is the ratio of molecular thermal and momentum diffusivity. The Eckert number governs temperature increase through adiabatic compression. These same parameters can be obtained from a simplified energy equation for an incompressible fluid with constant therma) conductivity, but the above interpretation (which is the correct one for heat engines) of the Eckert number is then no longer valid. If the temperature difference $\Delta T_{0}$ is of the same magnitude as the free stream temperature $T$, the Eckert number is directly comparable to (and dependent on) the Mach number (Schlichting 1979), but in this Tow-speed case, it is a distinct parameter.

A Nusselt number, containing the film heat transfer coefficient, comes from the condition of conduction at the boundary. The temperature or heat flux at this boundary also depends on a time-varying conduction equation, including a storage term, for the matrix. Additional similarity parameters, not specified here because of the wide choice of normalizations, arise from this conduction equation. 
The geometric parameters for the one-dimensional problem are the same as for the momentum case, and are unknown for complex regenerator matrices. It is useful to note that in other heat transfer problems with complex geometries, data are gathered for each geometry without trying to specify governing geometric parameters. Though laborious, this may be necessary for regenerators as we11.

\subsection{REGENERATOR CHARACIERISTICS}

To further illustrate the many possible phenomena and alternate formulations of important parameters applicable to regenerators for Stirling and similar applications, Table A.1 in Appendix A offers a listing of regenerator characteristics, their effects, and parameters used in description of those effects in the literature. Most of the parameters could be specified equivalently by the similarity parameters derived here but, in general, too few data are available in papers on the phenomena to rigorously complete the transformation of experimental results. The origins of the parameters are straightforward, however.

All the characteristics under the heading of FLOW OSCILLATION--frequency, waveform, amplitude, and reversal length--arise from the momentum equation and depend on Reynolds number, kinetic Reynolds number, a combination of the two, or, in the case of waveform, possibly an alternative formalation of the kinetic Reynolds number that does not assume sinusoidal flow. The enhancement of conduction in high-frequency flows also depends on the energy equation and thus includes the Prandt l number as well.

Characteristics categorized under FLOW NONUNIFORMITY IN MATRIX also depend largely on the momentum equation, and thus on the two Reynolds numbers, but also include Prandt 1 number from the energy equation (to specify thermal boundary layers) and geometrical parameters such as length/particle diameter. The matrix microstructure, under MATRIX PROPERTIES, consists entirely of currently unspecified geometrical descriptors. PRESSURE OSCILLATION is described by the Eckert number from the energy equation, and the ratio of specific heats, which could also have been derived if an equation of state (e.g., perfect gas) had been included in the equation set. The STEEP GRADIENT IN THE FLOW DIRECTION is 
the result of the imposed boundary and initial conditions on the energy equation, and as a result rather than a cause its parameterization depends on whether the solution procedure being used can handle the gradients and their effects on flow properties.

\subsection{ENGINE FLOW DATA}

In a recent paper (Seume and Simon 1986) the dimensionless frequency, amplitude Reynolds number, and amplitude ratio have been calculated for heat exchangers in a number of Stirling engines. While perhaps not typical of all the heat engine cycles in which regenerators are important, these data give a good idea of the flow regimes of interest. The numbers are based on simple isothermal Stirling cycle analysis and engine information collected from a variety of sources. The figures do not include the effect of not operating each machine at its specified design point. This is very important, as several potential Stirling engine applications require good part-load performance. For many engines the potential operating region covers a wide range of flow parameters, and may include fundamentally different types of flows.

The values of the Stirling engines' similarity parameters are given in Figures 3.1 and 3.2. The parameters vary considerably because the engines have been designed using different methodologies and for different purposes. Some are aimed at extremely high efficiency, others at very high power densities, others at modularity for ease in research and testing, and so on. Different engines may also have fundamentally different types of flows. These roles and the symbols used for the engines are detajled in Table A.2 of Appendix A.

\subsection{CONCLUSION}

This chapter has introduced the fundamental equations governing regenerator operation and discussed the controlling parameters arising from those equations. These are the similarity parameters that must be used to ensure the relevance of experimental data to heat engine conditions. A more intuitive presentation of the same ideas has been presented in Table A.1, and the relationship between the two presentations briefly outlined. Finally, the flow 


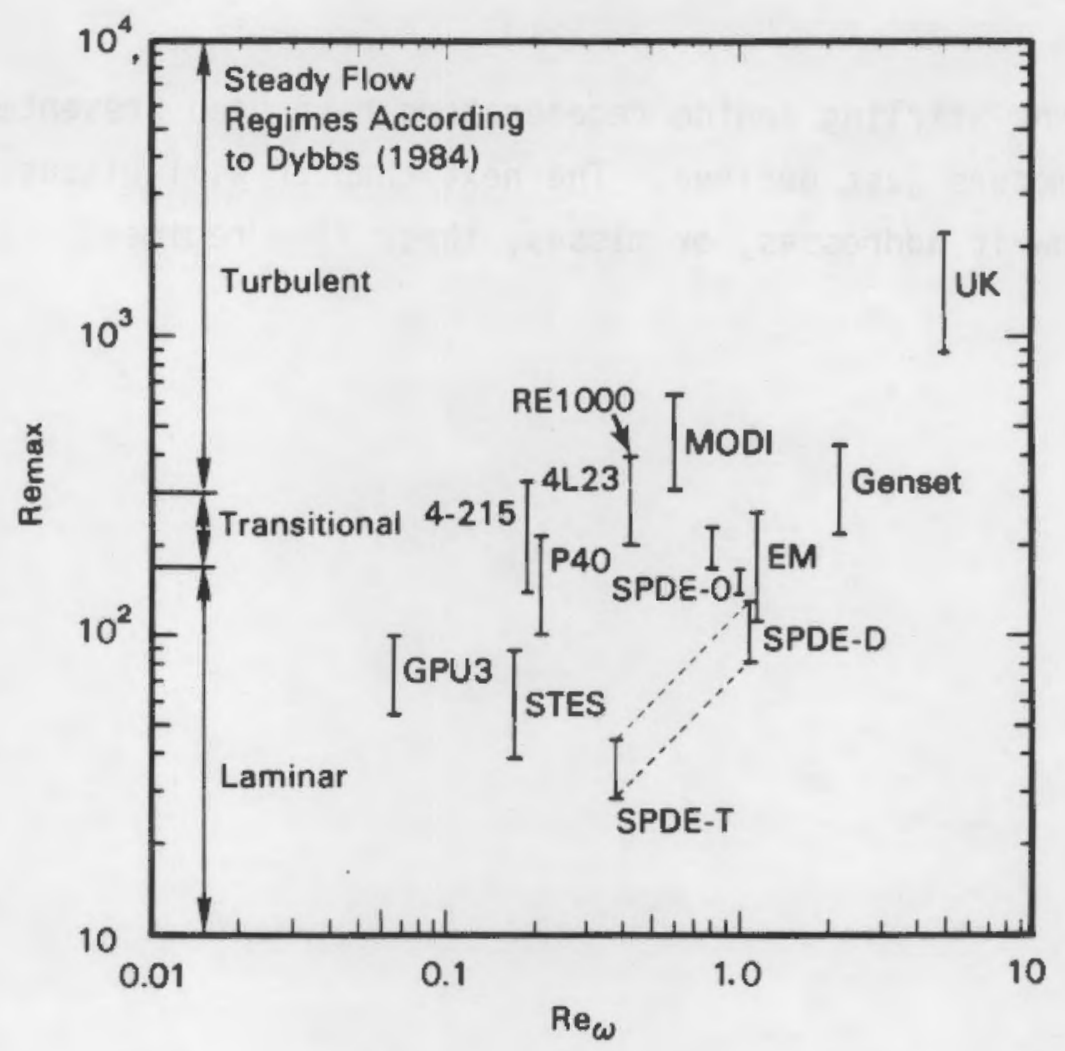

FIGURE 3.1. Reynolds Number Versus Dimensionless Frequency (Seume and Simon 1986) (Adapted from material copyrighted by the American Chemical Society; used with permission.)

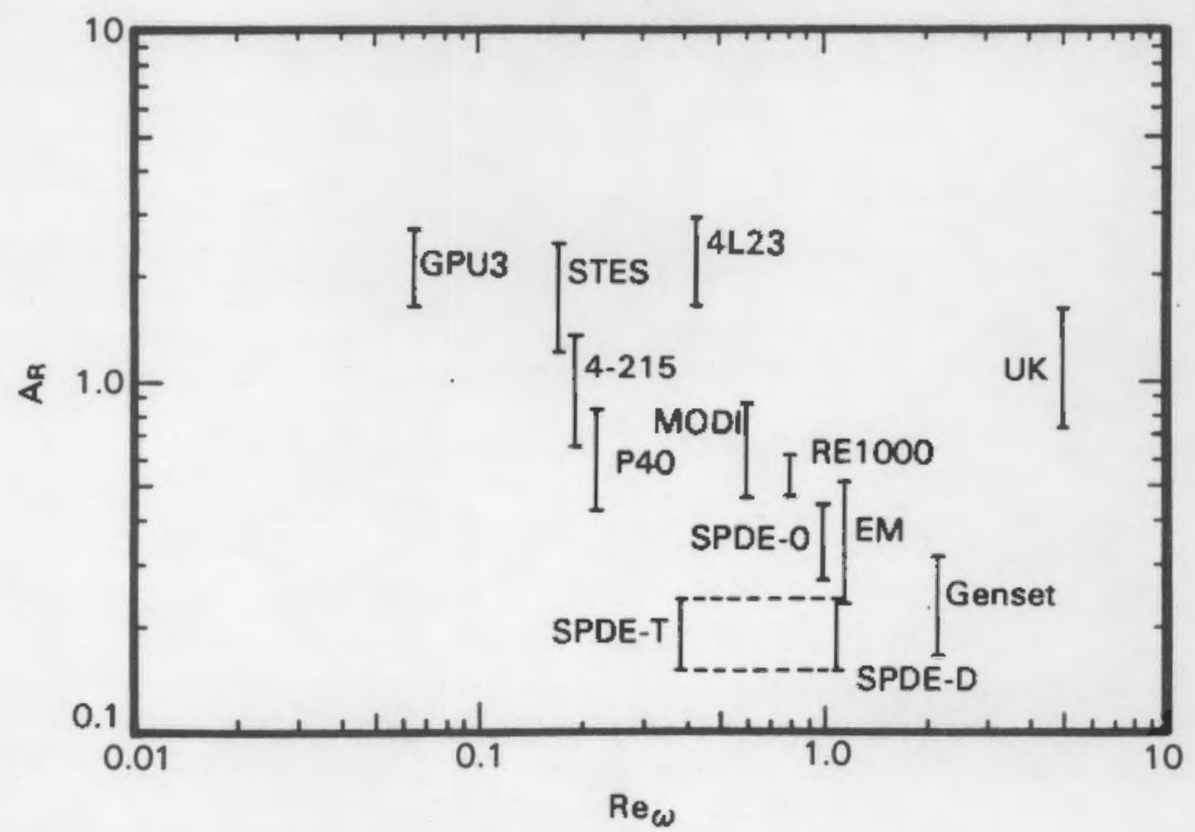

FIGURE 3.2. Relative Amplitude of Fluid Motion Versus Dimensionless Frequency (Seume and Simon 1986) (Adapted from material copyrighted by the American Chemical Society; used with permission.) 
regimes in current Stirling engine regenerators have been presented using the similarity parameters just derived. The next chapter will discuss available data and show how it addresses, or misses, these flow regimes. 


\subsection{EXISTING DATA ON FRICTION AND HEAT TRANSFER}

Experimental data can be grouped into two sets: data commonly used in regenerator design in the past, and data deriving from specific tests of heat engine regenerators in more realistic (oscillating) flow conditions. A previous report (Finegold and Sterrett 1978) summarizes the first set of data; more recent steady flow results and oscillating flow data are presented in Table A.3 of Appendix A. This chapter discusses steady flow and oscillating flow data and experimental methodologies, paying particular attention to shortcomings in the data as applied to the heat engine application.

\subsection{STEADY FLOW DATA}

Data used in past regenerator design and heat engine analyses have basically come from "steady" flow heat transfer and friction testing. Quotation marks are used because the flows used for heat transfer are seldom actually steady; the tests are quite difficult and accuracy is often obtained by using step changes or sinusoidal variations in temperature. The data do not, however, include any information about frequency, and $\mathrm{Re}_{\omega}$ is not part of the correlations. Most correlations include a Reynolds number and a friction factor or Nusselt or Stanton-Prandtl number combination. None give an Eckert number.

Many of these correlations have their roots in the extensive heat exchanger testing done by Kays and London of Stanford in the 1950s and 1960s (Kays and London 1984) to provide the knowledge base necessary to design regenerator matrices for gas turbines. A number of experiments that provide the technology base for process design have also been done by chemical engineers, who treated packed beds of many types in both gas and liquid flows. These data have been summarized by Barker (1965) and Gupta et al. (1974), among others. Finally, researchers on Stirling and other heat engines have developed some steady flow correlations themselves, including cryogenic work at the National Bureau of Standards in Colorado, in Canada (Walker and Vasishta 1970), in Japan (Miyabe, Takahashi and Hamaguchi 1982), and a variety of proprietary work at private companies. 
A number of important points arise from review of this work and are discussed in this section. First, the flows tested are non-Darcy flows, as turbulence or other noninertial effects are important. Second, many different approaches to geometric parameterization have been used, but there is still little agreement at present. Third, the testing itself is quite difficult, for the thermal storage taking place in the regenerator is not steady, and direct measurement of the heat transfer taking place has not been possible. Finally, the quasi-steady assumptions used to justify the application of steady flow data to unsteady flows in heat engines are questionable.

\subsubsection{Non-Darcy Flow}

The correlations for friction in the tested flow, such as the steady flow examples in Table A.3, show that the flows are non-Darcy (in which friction factors are not strictly dependent on viscous effects) for they are not inversely proportional to Reynolds number (and velocity). This occurs because these flows are fast enough for inertial effects--flow separation, form drag and perhaps turbulence, each of which scale with velocity squared--to be important. These effects must not be confused with acceleration effects in oscillating flows, which can also add a non-Darcy term to pressure drop but are not generally important in heat engine regenerators.

\subsubsection{Geometric Parameterization}

There is considerable difficulty deciding how to correlate the data for both friction and heat transfer, particularly with respect to the length scale used. Some workers, including Kays and London (1984), chose to report each geometry and porosity separately for friction and heat transfer. Recorrelation of Kays and London measurements (Chen and Griffin 1983), using wire diameter (instead of a more conventional hydraulic diameter) as suggested by Miyabe, Takahashi and Hamaguchi (1982), helped collapse their data. There are many other approaches, however. Work on non-Darcy flows through screens (Beavers and Sparrow 1969) indicated that, when used as the length scale in the Reynolds number, the square root of permeability (measured from pressure drop in the Darcy regime) was able to collapse data from matrices with varying meshes and porosities but the same overall type of geometry. 
The chemical engineering community has used porosity directly (Gupta et al. 1974) in heat transfer correlations; such treatment also recreates the dependence of Kays and London data on porosity very well (Hutchinson and Lyke 1987). It has recently been suggested, however (Dybbs et a1. 1984), that the use of the length/diameter ratio of a typical pore in the matrix as a separate nondimensional parameter was necessary. Treatments (Vafai, Alkire and Tien 1985; Vafai and Tien 1981) from chemical èngineering invoke local averaging, and, on the basis of a number of empirical parameters necessary when using such averaging, can treat not only friction and heat transfer but also nonuniformities and entrance effects in regenerators. These results are discussed in the next chapter.

\subsubsection{Experimental Difficulty}

The complications of steady flow testing are not to be taken lightly, particularly for thermal experiments. Friction measurement is simpler, for the experiment actually reaches a steady state, and methods to accurately measure pressure drop in such flows are not too difficult if flow profiles are known. In the case of friction, key concerns are problems with regenerators themselves--they are currently made by hand and can vary a great deal. They may also have significant nonuniformities that can affect their performance strongly, as discovered by Jones (1982b). The fit between the matrix material and the regenerator casing is a typical problem, leading to a strongly nonuniform flow profile.

Thermal measurements are tougher to make because regenerators are not steady-state devices; instead, they depend on the transient thermal storage in the matrix material for their operation. Production of "steady flow" results is often artificial, designed to be useful to the analyst for applications in which the dynamics of the heat transfer are not important or are otherwise discounted. A number of different regenerator thermal tests are possible, including internally heating the matrix material and using steady flows, thermal step function testing in a variety of ways, and even using sinusoidal flows more similar to Stirling conditions than the steady flow form in which the results 
are reported. The latter thermal frequency response tests, carefully developed to give results suitable for application in analysis following quasi-steady assumptions, may be the most effective "steady state" tests (Stang 1970).

\subsubsection{Quasi-Steady Assumptions}

The quasi-steady assumptions certainly hold true for the gas turbine applications that drove the experiments of Kays and London, Stang, and many others. Gas turbine regenerators receive long, steady, periodic blows, and the residence time of any particular gas particle in the exchanger is very short. The assumptions are unlikely to hold true for most closed cycle heat engine regenerators and other heat exchangers with gas particle residence times of the same order of magnitude as the blow time (Organ 1975). Analysis of a simpler application helps explain why. Looking at oscillating flow in pipes, for which analytical solutions exist (Schlichting 1979, Seume and Simon 1986), shows that the velocity profiles from which friction factors are derived are totally different from what would be predicted using quasi-steady assumptions. Chen and Griffin (1983) have noted that in pipe flows this holds only for higher $\operatorname{Re}_{\omega}$ flows, in which frequency effects are strong. Flow in regenerators probably has a lower $\mathrm{Re}_{\omega}$, but there are geometrical assumptions involved both in applying pipe flow results to regenerators and in calculating $R_{\omega}$ for regenerators that are not resolved. Thus selecting a particular $R_{\omega}$ that determines whether the quasi-steady assumptions are valid is a very uncertain exercise. It must not be forgotten that long residence times of gases in some regenerators are a fact and the analysis approach used should reflect it.

\subsubsection{Steady Flow Summary}

This examination of steady flow results shows that the heat engine regenerator application is quite different from the applications that have driven tests of porous media and matrix materials in the past. It is typically neither a Darcy flow nor, perhaps, a quasi-steady flow. The past steady flow work treated non-Darcy flow aspects, but did not in general solve difficulties of length scale in the resulting correlations. Early researchers often treated such problems very cautiously by providing separate data for each change of geometry and porosity. Later work has suggested many different approaches, but 
no complete treatment of the problem has been produced (in the public literature) for the heat engine application. Indeed, the whole idea of using steady flow results may be suspect. Using the quasi-steady assumption when developing data for and analyzing Stirling heat exchangers is, in many respects, a last resort (Urieli and Berchowitz 1984) because until very recently there have been no other data. Once this fact became clear to researchers, the next step was to do experiments that did not require a quasi-steady assumption, i.e., experiments on oscillating flows. The early results will be reviewed here.

\subsection{OSCILLATING FLOW REGENERATOR DATA}

Oscillating flow experiments are now an area of considerable activity among those interested in heat engines. The first new experiments in tubes or ducts, typically using water (Dijkstra 1984; Taylor and Aghili 1984), are not treated here; they are effectively reviewed in (Seume and Simon 1986). New regenerator results are just beginning to be reported. 0lder results include the work of Murray and Martin (1961) and Rea and Smith (1967). After noting that the shape of the flow oscillation affected heat transfer more than the frequency in a 0.5-to $3.3-\mathrm{Hz}$ range, Murray and Martin returned to steady flow testing because of the difficulty of the experiments (Bayley and Rapley 1961). Rea and Sinith (1967) made tests on oscillating flow heat transfer in a packed bed that showed little change from steady flow results.

The more recent efforts include a far more complex approach undertaken at Reading in England (Rice et a1. 1983; Rice, Thonger and Dadd 1985). After several years, painstakingly averaged heat transfer data, as well as some lowfrequency ( 7 to $11 \mathrm{~Hz}$ ) pressure traces deviating markedly from the smooth sinusoidal ones produced by today's codes, have been presented. Work in a sophisticated rig at Argonne National Laboratory has produced some similar pressure traces (Roach 1986, Krazinski et al. 1986). The correlations from oscillating flow experiments are summarized in Table A.3 in Appendix A. Figure 4.1 sketches where all available results are estimated to fit on the Stirling engine flow regime as detailed in Figure 3.1. The Galitseiskii and Ushakov data (1982) in Figure 4.1 are from porous media research in Russia, and 


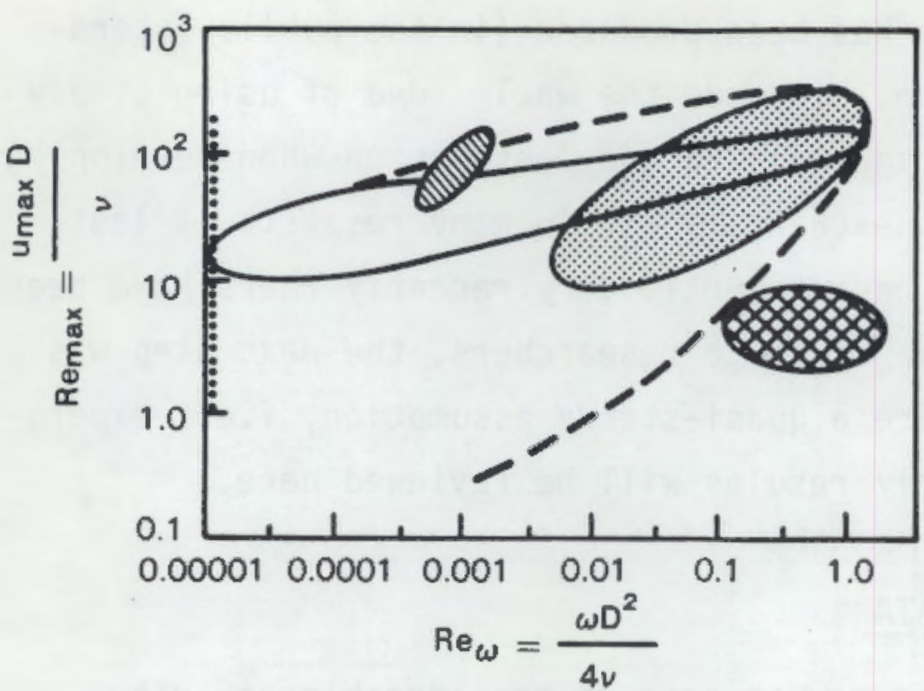

Friction Results with Unavailable $R_{e} \omega$ (Nakajima et al. and Other References)

Reading Dynamic Test Rig Heat Transfer Data (Rice et al.)

Stirling Engine Off-Design Operating Point Region

Air Engine Heat Transfer (Murray and Martin)

Modern Stirling Engine(s) Design

Operating Point Region

Galitseiskii Data

\section{FIGURE 4.1. Experimental Results Within Stirling Regenerator Flow Regime}

are included to point out that results from other fields may be relevant to heat engines. Porous media are discussed in the next chapter.

\subsubsection{Experimental Problems}

Perhaps the key observation from work to this point is that oscillating flow regenerator experimentation is extremely difficult, and the uncertainty of early results is high. Most groups to attack the problem, beginning with Murray and Martin (1961), have had difficulty obtaining reliable results. Only one group has run tests at realistic frequencies thus far, and the data required to calculate kinetic Reynolds numbers for these constant volume pressure drop measurements were not published (Nakajima, Kohno and Azetsu 1985). Each of the two major efforts (Reading and Argonne) to design a realistic experiment, with a good thermal gradient through the regenerator, realistic speed of operation and sinusoidal flow waveform, has run into problems.

The Reading group (see Figure 4.2 for rig schematic), which in the five years since their constant volume rig's development has exercised the rig considerably, has had sealing problems and nonuniform heating problems that strongly degraded measurement accuracy (Jones 1982b). To make thermal measurements an ultrasonic thermometry technique was developed (Dadd 1982) requiring assumptions about the nature of flows in the rig in order to produce a measurement. No uncertainty analysis was reported for this arrangement; in addition, 


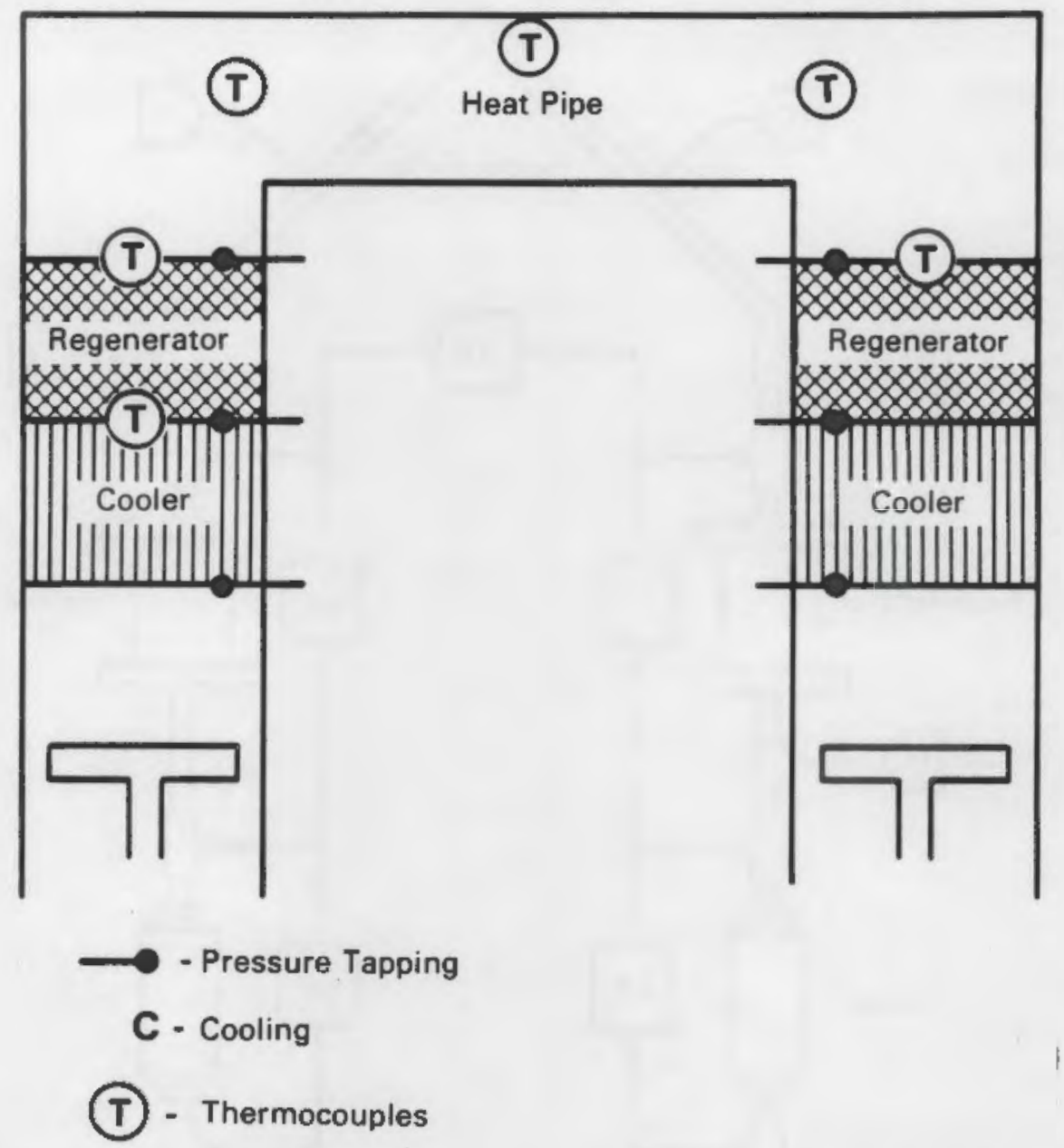

FIGURE 4.2. Schematic Diagram of Reading Test Section

the nature of the flow being tested affects the desired thermal results, so making assumptions about the flow diminishes the ability of the experimenter to examine the physics in the rig.

The Argonne group (see Figure 4.3 for rig schematic) has not yet reported thermal measurements and is still in the early stages of their experimental program. With their experiment, however, they must compute velocities based on assumptions about flows in the rig (Roach 1986), thus making assumptions about what may be controlling phenomena in a manner similar to Reading's thermal measurement. This severely limits the value of Argonne's ability to simulate variable volume operation and simulate a realistic Stirling cycle. Argonne has 


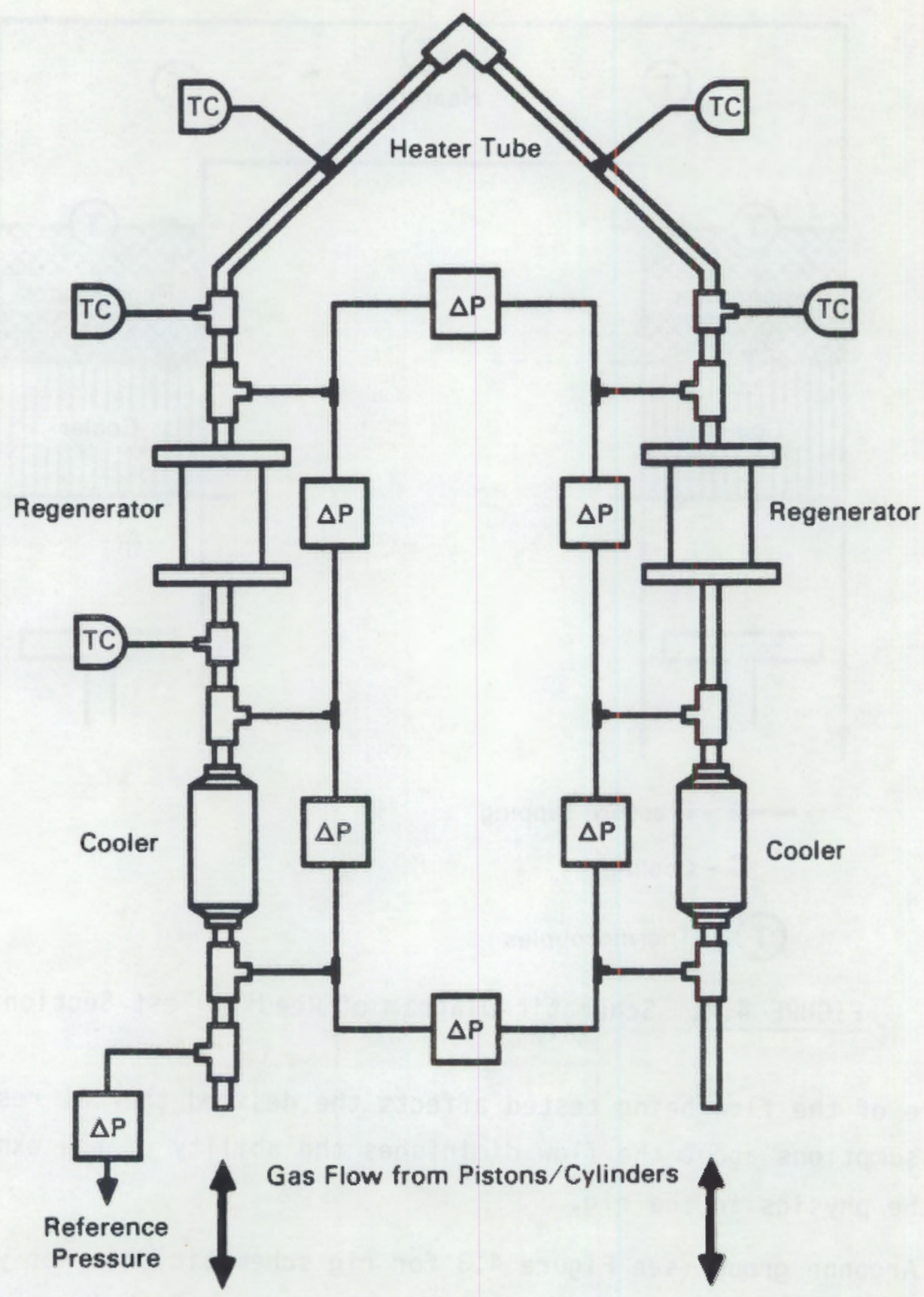

FIGURE 4.3. Schematic Diagram of Argonne Test Section (Roach 1986)

also had curious results from their pressure measurement system, which gives extra $200-250 \mathrm{~Hz}$ signals that have avoided explanation. Although apparently not directly affecting measurements of pressure variations at the rig's 
operational frequencies (below $50 \mathrm{~Hz}$ ), resonances and other problems recur in making this type of measurement in many applications. Related pressure wave phenomena may play a key role in some heat engines, particularly free-piston Stirling devices. Reviewed from this perspective, the problems that Argonne and Reading faced in developing realistic experimental rigs include many of the problems inherent in building and testing a full working Stirling engine.

\subsubsection{Simplifications Used}

These problems have occurred despite the careful attempts to make measurements more feasible by "leaving out" certain characteristics of working engines in the design of the Argonne and Reading experimental rigs. Reading avoided variable volume operation and used heavy gases (nitrogen) and low-speed operation to avoid excessive leakage (Jones 1982b). Argonne opted for a long, thintube rig geometry to try to spread out and simplify measurements (Roach 1986), which in turn made flow measurement close to impossible and made acoustic resonances and other acoustic effects more likely. The choices made to simplify the experiments have thus created problems of their own that have sacrificed accuracy and realism. Those choices have not resulted in experiments simple enough to produce the expected range of new results or insights in the five years or so since each rig was designed.

Using a different approach early in their Stirling research programs, the Japanese built special engines for making test measurements (Mitsuda et al. 1985). Details of these rigs are in papers published in Japanese. These engines were very inefficient and crude but could be instrumented almost as well as the Argonne rig in current form, although they lacked its flexibility. It is difficult to say how valuable the results were, since a crudely operating Stirling engine may have vastly different flow and thermodynamic characteristics than a powerful and efficient one. But there is a fine line between "realistic" experiments and running engines; both suffer measurement difficulties that severely limit the amount of understanding that can be gained from them. 


\subsubsection{Regenerator Testing Approach}

Both the Argonne and Reading experiments were designed to produce improved correlations for designers to use in developing new engines. Unfortunately there is still considerable uncertainty over how to correlate data, or even exactly which parameters to measure. The correlations from the Reading work, shown in Table A.3, do not use the similarity parameters that were shown in Chapter 3.0 to be among those determining regenerator behavior, nor are boundary conditions (geometry, including porosity) carefully treated. It is thus not clear that the lessons that might have been gained from experiences with steady flow experiments have been well learned, especially with respect to the effects of varying regenerator geometries. In addition, the requirement of matching the experiment to reality with a full set of similarity parameters, as well as matching it to the analytical methods used to analyze the regenerator, must be clearly understood. In the current regenerator work, the choice of measurements is driven more strongly by time, resources, and available measurement technology than by the actual need to understand new physics.

\subsubsection{Data Analysis}

Uncertainty about this new physics requires very careful and explicit averaging and also very explicit and careful data reduction. The effect of averaging is very important and frequently underestimated (Jones 1985). The type of averaging used to reduce the data (or used implicitly in making the measurement) must match that used to apply it in analysis; otherwise, the results simply do not apply to the analysis without gross, unintended assumptions (Hutchinson and Lyke 1987). For example, Reading carefully averaged its early oscillating flow heat transfer results over a cycle (Rice, Thonger and Dadd 1985), using a finite element method, to develop a dataset for design. The resultant correlations cannot be used in sophisticated Stirling codes because the codes require correlations for "instantaneous" friction and heat transfer that apply to a portion of a regenerator for a portion of a cycle. The most detailed oscillating flow heat transfer data taken to date were thus presented in such a way that they were not usable by state-of-the-art codes. 


\subsubsection{Oscillating Flow Summary}

All oscillating flow friction and heat transfer experiments have been very difficult. Key efforts in England and the U.S. have approached the problem with very sophisticated rigs aimed at testing a wide variety of regenerators and other components. The difficulties encountered in making these experiments operational have forced limitations on operating regimes and use of additional assumptions about the nature of flows within the rigs, with the result that the experiments cannot be relied upon for fundamental understanding. Indeed, given current measurement technology, a suitable alternative to such rigs intended to provide component test data might be to improve instrumentation on a working engine, an approach that has met with some success in Japan. Perhaps because of the many experimental limitations, past experimental efforts have given too little emphasis to similarity parameters: Eckert number and kinetic Reynolds number are simply not mentioned in reporting of results. Instead, customary steady-flow forms are used. Finally, despite an avowed effort to provide results usable to designers, little attention has been paid to the data actually required by heat engine design codes. Improved coordination between experimenters and analysts is required.

\subsection{RESEARCH NEEDS}

Given all the complications outlined above, there is a strong need for improved fundamental knowledge of oscillating flow. Such work will have to provide a basis for understanding, directing, and guiding regenerator testing, which should in turn provide the numerical information necessary for design. The ability to directly visualize flows with at least limited physical similarity to heat engine flows would be extremely valuable and should not be considered impossible. Work in rigs with measurement limitations such as those at Argonne and Reading, should concentrate on the accuracy, analysis and presentation of the data that can be measured and can be demonstrated via similarity analysis to be relevant to key applications. Improved cooperation with heat engine analysts to work out experimental goals and necessary accuracies is 
important. Researchers should continually recognize the importance of developing self-consistent sets of assumptions with which to attack regenerator problems.

There is also a great deal to learn from researchers outside the heat engine field who have completed fundamental work relevant to regenerators. It is also worthwhile to review the fundamental research done with Stirling engines in mind. The next and final chapter of this report introduces several areas of fundamental work that have seen recent activity for a variety of reasons and are of importance for heat engine applications. The development of fundamental knowledge about regenerators should build on these efforts. 


\subsection{DATA FROM FUNDAMENTAL INVESTIGATIONS}

This chapter outlines basic experimental results and analytical approaches that illuminate some of the physical phenomena that may be active in a heat engine regenerator. Rough calculations are performed for some of the phenomena to determine their possible relevance to a General Motors GPU-3 Stirling engine, a particularly well-documented heat engine. Because of the wide variability in operating conditions and flows between machines, however, the importance of various phenomena to current heat engines may differ widely.

Four separate topics are covered in the chapter. They were selected from the literature because of perceived relevance to heat engine regenerators and evidence of recent scientific activity and progress. The first topic concerns the effects of compression and expansion on heat transfer. It has been investigated with heat engines in mind, but as yet includes extremely limited experimental evidence. The second topic, enhanced conduction in laminar oscillating flow, is also known to Stirling researchers. The third topic, on alternative analysis methods for porous media, includes as an example the effects on heat transfer of nonuniformities such as those occurring in regenerators. The final topic treats possible heat transfer enhancement mechanisms in porous media.

\subsection{HEAT TRANSFER DURING COMPRESSION AND EXPANSION}

The compression and expansion of the working gas in Stirling, Otto, diesel and other heat engine cycles can have significant effects on gas temperatures and heat transfer. This compression/expansion effect can be important if the time a gas particle resides in the space is not small compared to the cycle time, e.g., if the amplitude ratio $A_{r}$ (Seume and Simon 1986; Organ 1975) is not much greater than one. This is the case for the cylinders as well as the regenerators of many Stirling machines, and also for a variety of other reciprocating machinery including internal combustion engines and compressors and gas springs.

When dealing with compression/expansion heat transfer to a surface, it is useful to view the situation as heat being absorbed or produced uniformly in 
a fluid or gas (Dijkstra 1984). This situation is fundamentally different from more conventional heat transfer formulations. For fully developed flow in pipes, ratios of $\mathrm{Nu}_{\mathrm{C}}$ (the Nusselt number for heat transfer to a constant temperature wall from a fluid that produces or absorbs heat) with the more common constant surface temperature condition Nusselt number $\left(\mathrm{Nu}_{\mathrm{t}}\right)$ or the constant surface heat flux condition Nusselt number $\left(\mathrm{Nu}_{h}\right)$ can be calculated at various flow rates. As shown in Figure 5.1, under laminar conditions, $\mathrm{Nu}_{\mathrm{c}}$ is about 1.6 times $N u_{t}$, while $N u_{h}$ is only 1.2 times $N u_{t}$. The thermal entry length is also much longer for $\mathrm{Nu}_{\mathrm{C}}$-type heat transfer, with both local and averaged $\mathrm{Nu}_{\mathrm{C}}$ much higher than $\mathrm{Nu}_{t}$ near the entrance of a pipe. These results indicate that the thermal boundary layers are quite distinctive for the heat source/sink case. When the heat source/sink is caused by alternating compression and expansion, and the boundary layers change in response, important losses can occur during the cycle.

A simple analytical treatment has been developed by Lee (1983), emphasizing the phasing of the compression and expansion heat transfer. Lee studied compression/expansion heat transfer with constant wall temperature in a onedimensional "gap" space, with emphasis on the phasing of the heat transfer. Beginning with a simple, time-dependent one-dimensional energy equation and treating fluctuations in gas pressure and temperature as harmonic and much

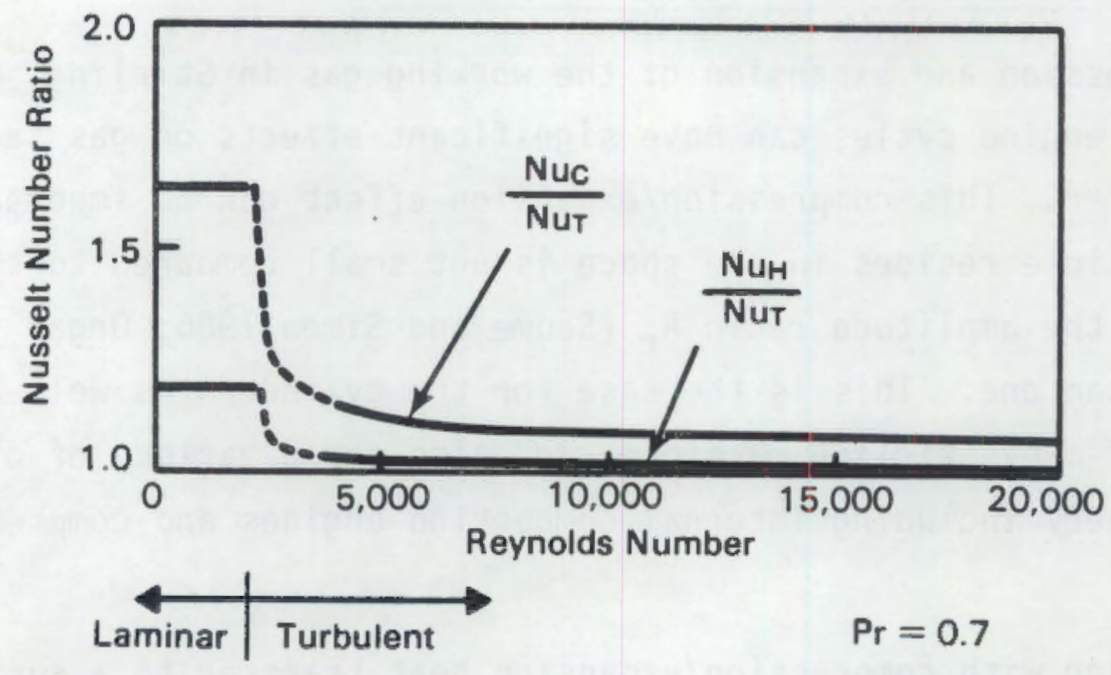

FIGURE 5.1. Compression/Expansion Heat Transfer Characteristics (Dijkstra 1984) (Adapted from material copyrighted by the American Nuclear Society; used with permission.) 
smaller than their mean values, Lee developed an expression for temperature distribution in the gap. The solution is strongly dependent on the ratio of gap width to thermal diffusion layer thickness, a function of gas thermal diffusivity and cycle frequency. Low values of this ratio (e.g., narrow gaps, low frequencies and high thermal diffusivities) have isothermal behavior; high values of the ratio have adiabatic behavior with heat transfer lagging the gradient by 45 degrees. Either case is acceptable, for as shown in Figure 5.2, it is only at intermediate ratios, and particularly near a ratio of 1.0 , that phase lag is such that serious power losses occur.

This type of cyclic heat transfer is being treated in an experimental effort at MIT in which gas is compressed in a cylinder, with pressure, volume and the ideal gas law used to determine temperature. In early work running with nitrogen, argon and helium, the researchers found that losses depended on Peclet or Reynolds number (which was averaged) and specific heat ratio (Faulkner and Smith 1983). More recent work with a modified apparatus has confirmed these dependencies and produced results that appear to be effectively correlated using the Lee model (Kornhauser and Smith 1987). Geometrical effects, flow regime changes, and other effects remain to be investigated.

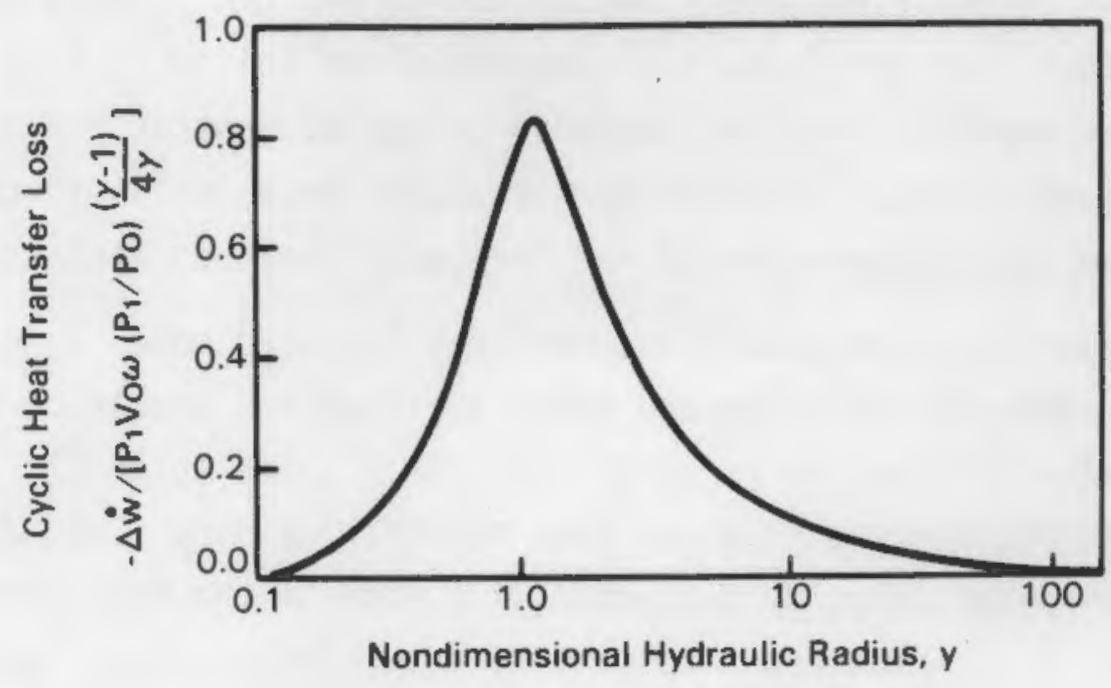

FIGURE 5.2. Heat Transfer Losses in Compression/Expansion (Lee 1983) (Adapted from and reproduced by permission of the American Institute of Chemical Engineers.) 
Applying the Lee results to the GPU-3 Stirling regenerator requires estimates for the gap width characteristic dimension and the effective thermal diffusivity in the regenerator. Neither of these are known. Following Lee's recommendations (enclosed gas volume divided by heat exchanger surface area for the gap width characteristic dimension, and the unrealistically low laminar thermal diffusivity) gives ratios ranging from about 1.0 down to 0.1 or less. The results depend strongly on the location (e.g., the temperature) in the regenerator, as well as the engine speed, and the gap width and diffusivity parameters. Thus the GPU-3 is somewhere on the "isothermal" side of the loss peak shown in Figure 5.2, but portions of the regenerator could still harbor substantial losses due to cyclic heat transfer. Because the heater and cooler and, most particularly, the working spaces of a Stirling machine function within a narrower hydraulic radius range on the loss curve in figure 5.2 and are far less likely to be isothermal, cyclic heat transfer may be of greater importance there than in the regenerator.

The above work and other efforts have shown that for cyclic heat transfer the heat transfer rate cannot be correlated with the difference between the mixed mean gas temperature and the wall temperature by means of a single heat transfer coefficient, as temperature does not vary monotonically with distance from the wall. In addition, power losses due to the cyclic heat transfer were quite significant; for instance, $4: 1$ compression of helium in a cylinder had a maximum (at intermediate Reynolds numbers) of $22 \%$ of compression work lost (Faulkner and Smith 1983). Further heat transfer research is certainly vital in order to isolate key geometrical and frequency dependencies.

At the same time, the mean-parameter heat transfer modeling used in more sophisticated codes for Stirling and other applications should be adaptable to new heat transfer information in this area. Such codes currently calculate working gas thermodynamics, flow and heat transfer at many times during a cycle and in several spaces, al ready accounting for some of the integrated effects now being seen in experiments. Analysis to determine accurate mean-parameter correlations that include frequency dependence and other factors should be feasible if experimental results continue to be encouraging. 


\subsection{ENHANCED CONDUCTION IN LAMINAR FLOWS}

A second effect that could be of importance in a variety of higher frequency oscillating flows is the enhancement of longitudinal thermal diffusivity. Originally noted in mass diffusion, the analogous behavior for heat transfer was experimentally noted by Kurzweg in laminar oscillating flow in thin capillary tubes (Kurzweg and Zhao 1984; Kurzweg 1985). This effect has been noted by researchers familiar with heat engine technology (Chen and Griffin 1983; Gedeon 1986; Seume and Simon 1986), particularly since the coolers in some engines take the form of bundles of thin, brazed tubes similar to those in the Kurzweg experiment. The effect would be one to avoid in regenerators, which must be expressly designed to avoid longitudinal heat transfers as much as possible. The implications of the research findings in this area will be discussed here.

The research by Kurzweg and coworkers treated flows in narrow capillary tubes or parallel-plate channels connecting hot and cold reservoirs that were subjected to high-frequency oscillations with small tidal displacements $z$. This resulted in very large axial heat conduction rates even though there was no net convective mass transport. This occurred because in such oscillating flows, fluid elements at different radial positions have different velocities and displacements (Seume and Simon 1986). Heat is transferred radially to fluid particles which then move axially to colder regions where they provide the heating. This mechanism is thus dependent on having a high-frequency flow that sets up such nonuniform velocity profiles. A minimum kinetic Reynolds number of about 100 has been proposed (Gedeon 1986; Kurzweg and Zhao 1984), and most conventional wire-mesh regenerators for the Stirling application have kinetic Reynolds numbers near one. As it is also unlikely that today's mesh regenerators have fully-developed laminar flow, the enhancement mechanism as analyzed is not likely to be a problem with current regenerators.

The topic still contains some uncertainties, however. While the ideal cases analyzed indicate a kinetic Reynolds limit far higher than what is expected in regenerators, experiments showed enhancement at somewhat lower numbers (Kurzweg and Zhao 1984); there was also some experimental indication that the mechanism might still be active in transition or turbulent flows. There 
has been no work to see if the mechanism would operate in a geometrically interrupted flow like that through a stacked mesh regenerator. Although current Stirling regenerators, for example, appear to be outside the regime for this effect, its existence and mechanism must be well understood in developing innovative future designs. One promising new regenerator approach, foil regenerators with long, thin flow tubes, seems to avoid the effect. But in innovative concepts such as liquid working fluid engines and in tubular regenerator geometries aimed at decreasing friction losses and costs, it is possible that this phenomenon could provide an unpleasant surprise.

\subsection{GENERAL SOLUTIONS FOR POROUS MEDIA}

The fundamental work discussed up to this point in this report requires one to guess at effective diameters or other geometric parameters to use in treating flow through a regenerator. The regenerator on the GPU-3 Stirling engine, consisting of $0.004-\mathrm{cm}$ diameter stainless steel wires in a mesh of $79 \times 79$ strands per square cm, with 309 layers of mesh packed into a small tube 2.26-cm long, is a typically tough application. Exact threedimensional analysis of flows through such a medium cannot yet be done, and thus the problem is collapsed into one dimension. A number of different effective diameters have been used, primarily for data reduction, with some more effective (Chen and Griffin 1983) than others. This is not a new problem to researchers accustomed to dealing with porous media, however.

A generalized analysis approach has been developed for steady, incompressible applications (Vafai and Tien 1981; Vafai 1984; Vafai, Alkire and Tien 1985). It treats porous media by way of "macroscopic" equations, based on averages over small volumetric elements, with the help of empirical relations for specific physical terms in the fundamental transport equations. Key empirical parameters beyond common geometrical parameters and fluid properties (for the steady, incompressible case) are permeability and effective conductivity; both have been studied in great detail and their application is understood on both empirical and analytical grounds (Scheidegger 1974; Tien and Vafai 1979). A similar depth of understanding may well be required for the unsteady, compressible flows of heat engine regenerators. 
Some of the steady flow results obtained by Vafai and Tien using their explicit treatment of porous media are instructive. Regenerators are typically confined by external casings, a factor which, particularly in the case of annular regenerators, could be important in determining performance. Vafai and Tien found that although the boundary effect for the flow field is confined to a very thin momentum boundary layer insignificant to overall flow consideration, boundary and inertial effects can reduce heat transfer from the porous medium to the fluid by up to $50 \%$ (Vafai and Tien 1981; Vafai 1984). This effect is especially pronounced if the thermal boundary layer is of the same order or thinner than the momentum layer, as might be expected with large pressure differences, strong inertial effects, and a short boundary length such as occurs in a Stirling regenerator. Although results for steady, noninertial flows are of little interest in Stirling analysis, the possible role of boundaries in regenerators is a new factor to be examined experimentally and noted in design.

A second case examined by Vafai (1984) is variable porosity, typically occurring in beds of spherical particles (due to geometry) and near the wall of packed wire mesh regenerators [due to manufacturing (Jones 1982b)]. The effect of this nonuniformity on heat transfer is a function of Reynolds number (based on pore diameter), free-stream porosity and Prandtl number, permeability, matrix geometry, and the length of the boundary wal1. The boundary and variable porosity effects were found to double the rate of heat transfer to the wall in the reported experiment; this was in good agreement with numerical results explicitly treating these effects. It is apparent that variable porosity is yet another factor capable of increasing regenerator losses.

\subsection{HEAT TRANSFER ENHANCEMENT IN POROUS MEDIA}

Vafai and Tien were able to verify the results of their analysis by experimenting with porous media made up of packed spheres, a far more tractable medium than the typical heat engine regenerator. It permits internal temperature and even flow measurements, as well as use of simple characteristic lengths based on analysis. Recent experiments and analysis have taken advantage of this tractability to examine the heat exchange process in such a 
medium, including the effect upon this process of high-frequency oscillations in the heat exchange fluid flow (Galitseiskii and Ushakov 1982).

In contrast to other porous media studies in which the flow through the structure was modeled by parallel capillary channels or alternating constrictions and expansions in a flow channel, the flow was assumed to be analogous to a flow in a rough channel, in which the dimensions of the roughness (the mean statistical sphere diameter) were comparable to channel diameter. Such a flow was expected to be accompanied by the formation of stationary microvortices of sizes determined by the size of the packed spheres. In addition, the flow causes secondary vortices generated by its oscillations; these vortices have sizes dependent on the Stokes layer thickness. Thus heat exchange, with reference to the stationary case (subscript o), is

$$
\mathrm{Nu} / \mathrm{Nu}_{0}=F\left(\mathrm{Re}_{0} ; \mathrm{Re}_{\omega} ; \varepsilon\right)
$$

where $\varepsilon$ is the ratio of peak mass velocity in oscillating flow to that in steady flow (serving the same purpose as $R_{\text {max }}$ ). As in smooth channels (Schlichting 1979; Galitseiskii, Ryzhov and Yakush 1977), resonant phenomena might be expected when dimensions of the stationary vortices from flow over the structure are the same as the secondary vortices created by flow oscillations.

Experiments in the ranges of $\mathrm{Re}_{0}=0.6-6.0$, frequency $=20-400 \mathrm{~Hz}$, and $\varepsilon=5-150$ were performed with small test sections of nickel and stainless steel balls. The steady flow Reynolds number $\mathrm{Re}_{0}$ was based on estimated porous channel diameter. With oscillating flows, a peak in the heat transfer coefficient was found at 220 to $225 \mathrm{~Hz}$ ( $\operatorname{Re}_{\omega}=0.525$, based on particle diameter) for all $\mathrm{Re}_{0}$, with the effect increasing for higher $\mathrm{Re}_{0}$ and peaking at 4.3 times greater than steady flow at $\mathrm{Re}_{0}=6.0$. At this $\mathrm{Re}_{\omega}$ the ratio of particle diameter $d_{p}$ to oscillating Stokes layer thickness $b$ was 0.55 ; i.e., they are clearly comparable. This result, shown in figure 5.3 using a normalized scale, confirms the presence of resonant heat transfer enhancement phenomena in regular porous materials. The implications for interpreting steady flow test data for stirling engine use are interesting. If results are valid for $\varepsilon=1$ (the 


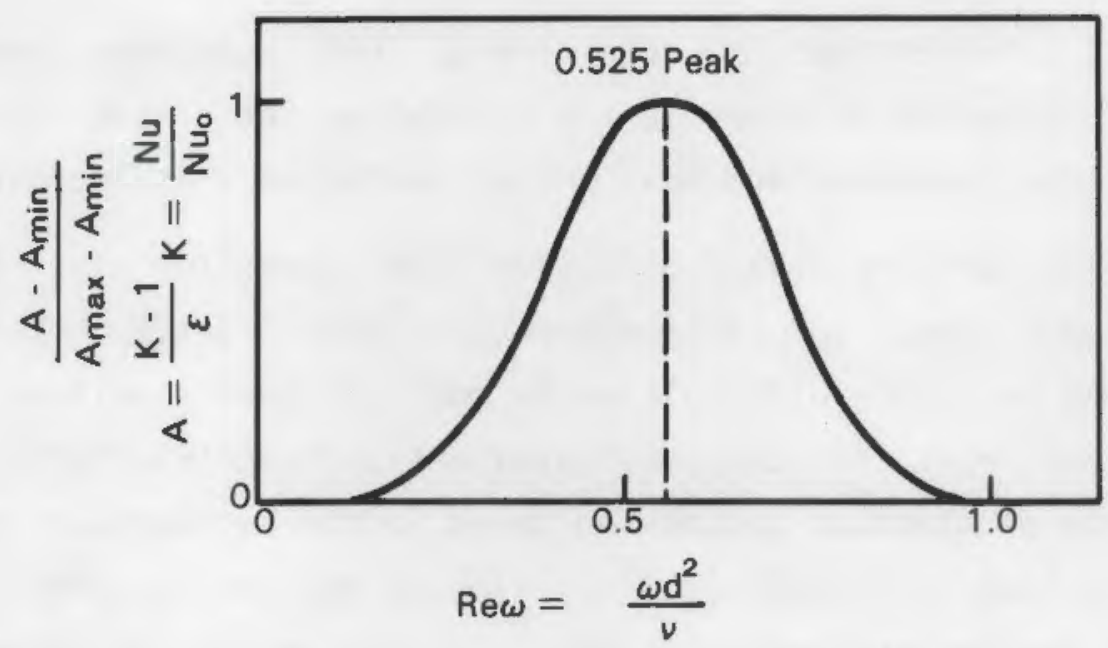

FIGURE 5.3. Heat Transfer Enhancement Oue to Oscillating Flow in Porous Media (Galitseiskii and Ushakov 1982) (Adapted from material copyrighted by Plenum Press; used with permission.)

smallest mass velocity ratio $\varepsilon$ tested was 5 , but unless steady flow results were all for Darcy flow or were otherwise qualitatively different from higher speed results, they could be valid), then at some $\operatorname{Re}_{\omega}$ (below 0.125 and above 0.925 , for the experiment described) the heat transfer in this type of flow can be exactly represented with steady flow data at the peak oscillatory mass flow rate. At other $\mathrm{Re}_{\omega}$ (between 0.125 and 0.925 ), the heat transfer ranges between the steady flow value and twice that value (here at the peak of $\operatorname{Re}_{\omega}=0.525$ ).

The ability of the length scale in $\mathrm{Re}_{0}$ and $\mathrm{Re}_{\omega}$ to capture the effects of more complex geometries than packed spheres must be determined, of course. But Galitseiskii and Ushakov's work provides perspective for examining new oscillating flow heat transfer data.

\subsection{DISCUSSION}

This chapter has presented experimental and analytical results from a variety of fields that describes phenomena that may be important in certain Stirling and other heat engine regenerators. The four topics discussed in detail may not turn out to always be the the most important, but rather were those that have received sufficient attention by investigators for useful insights to have developed at this time. Studying heat engine problems on the level of fundamental flow and heat transfer understanding has long been a key 
factor in successful engineering development. Continued investment in generic research on fundamental problems is now crucial as the connection between poorly understood phenomena and heat engine performance is becoming stronger.

For the four primary topics discussed, the connection with regenerators is different in each case. Compression/expansion heat transfer between the wall and the gas may not cause difficulties in most of today's well-designed regenerators, for instance. But compression/expansion heat transfer effects and their influence on stagnant and moving gases in the regenerator in Stirling cryocoolers is important today (Wolfs, Dijkstra and deJorge 1986), and wall heat transfer may be substantial in many heat engine and compressor cylinders. With proper understanding it can become a known factor in design, and perhaps can even be taken advantage of. Enhanced conductivity in laminar flows is also unlikely to occur in well-designed regenerators but has immediate implications for other heat exchangers in Stirling and other applications. Better knowledge of how this effect works in turbulent or compressible flows or in more complex geometries may prove invaluable.

Work focusing more particularly on flows in porous media, such as the well-meshed experimental/analytical methods of Vafia and Tien, or the intuitive experiments of Galitseiskii and Ushakov, has direct relevance to regenerator analysis and design. These approaches need more attention and work directed at regenerators. Other effects, such as the apparent enhancement of mass diffusion thermal diffusion in regenerators (probably caused by the way the matrix breaks up the flow and imposes local, radial velocity components) also require attention. In studying the effect of geometry on flow properties one cannot ignore the underlying question of whether flow in a given regenerator is turbulent. The nature of the flow in a given regenerator is the key to understanding which physical phenomena will be important: whether resonant vorticity generation can occur or what the local effective thermal diffusivity is, for instance.

Within porous media it is not known under what conditions turbulent, laminar, and transition flows occur and how these overlap. The onset of turbulence is known to be dependent on Reynolds number in pipe flows, with transition typically occurring somewhere above 2000. Jones (1982b) has noted that turbulence 
may occur within regenerators in oscillating flows at very low Reynolds numbers (10 to 20); Dybbs et al. (1984) suggested that in steady flow there was a transition region for $175<\mathrm{Re}_{\max }<300$. These numbers are 2 to 3 orders of magnitude lower than for oscillating pipe flows (Seume and Simon 1986). A primary cause is the disturbance to the flow caused by the matrix. Qualitative evidence of this effect comes from experiments in pipes where very small probe tips barely protruding into a tube shifted transition Reynolds numbers down by $25 \%$ (Merk $1 i$ and Thomann 1975), but the degree to which geometry can affect the onset of turbulence is not explicitly known.

Another way in which regenerator turbulence may differ from that in oscillating pipe flows is the likelihood for intermittent turbulence. In oscillating pipe flows, turbulence may not occur throughout a whole cycle except at very high Reynolds numbers. Instead flow becomes turbulent when the flow decelerates, then relaminarizes during acceleration (Hino, Sawamoto and Takasu 1976; Ramaprian and Tu 1980). But in regenerators the flow acceleration may not be sufficient to relaminarize the flow. In pressure drop regenerator tests done twice in a row in rapid succession, for instance, some regenerator geometries gave differing results the second time (Jones 1982b). This effect, presumably caused by residual vorticity, seems to be evidence of long decay times for small vortices in regenerators.

Full understanding of detailed flows in complex heat engine regenerator geometries may be both impossible and unnecessary. But more focused and fundamental analysis and experiment will provide very important insights into regenerator design. Good understanding of resonant heat transfer enhancements could make simpler, cheaper designs just as effective as today's packed mesh regenerators, for instance. Understanding of compression/expansion heat transfer and conductivity enhancement are also important building blocks for a variety of energy conversion applications and could be important for innovative regenerator approaches as well. Improved understanding will also make the nature and validity of the assumptions made in even the most sophisticated heat engine simulations clear, and will permit improvement of thermal modeling for best possible design results. 


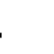

.

, 
APPENDIX A

TABLES 


\section{TABLE A.1. Stirling Regenerator Characteristics and Parameters}

\begin{tabular}{|c|c|c|c|c|}
\hline Characteristic & Physical Effects & Transport Effects & Parameters & References \\
\hline \multicolumn{5}{|l|}{ Flow nscillation } \\
\hline \multirow[t]{3}{*}{ Frendency } & $\begin{array}{l}\text { Iffert on Stokes layer } \\
\text { thickness }\end{array}$ & Enhanced conduction & $\operatorname{Pr}, a \sqrt{\omega / \nu}$ & $\begin{array}{l}\text { Kurzweg and } 7 \text { han } \\
1984\end{array}$ \\
\hline & $\begin{array}{l}\text { Effects on transition to } \\
\text { turbutence }\end{array}$ & $\begin{array}{l}\text { Roles of diffusion and } \\
\text { conduction ef fects in heat } \\
\text { transfer, amount of pres- } \\
\text { sure drop }\end{array}$ & $\frac{\omega v z^{2}}{v}, \frac{2 \hat{U}}{v w}$ & $\begin{array}{l}\text { Merk if and Thomann } \\
1975\end{array}$ \\
\hline & $\begin{array}{l}\text { E,ffectis on size, nature of } \\
\text { seconilary vertices }\end{array}$ & $\begin{array}{l}\text { Resonant enhancement of } \\
\text { ment of heat transfer }\end{array}$ & $\begin{array}{l}\mathrm{Re}_{4 \nu}, \mathrm{Re}_{\max }, \\
\text { geómetry }\end{array}$ & $\begin{array}{l}\text { Galitse1skii and } \\
\text { Ushakoy lya? }\end{array}$ \\
\hline Wayof orm & $\begin{array}{l}\text { Effects on condftional } \\
\text { turhulence--occurrence } \\
\text { of relaninarization }\end{array}$ & $\begin{array}{l}\text { Roie of diffusion and con- } \\
\text { duction effects in heat } \\
\text { transfer, amount of } \\
\text { pressure drop }\end{array}$ & & $\begin{array}{l}\text { Murray and Martitn } \\
1961\end{array}$ \\
\hline Ampl i ture & $\begin{array}{l}\text { Effect un transition to } \\
\text { turbulence }\end{array}$ & $\begin{array}{l}\text { Role of diffusion and can- } \\
\text { duction effects in heat } \\
\text { transfer, amount of } \\
\text { pressure drop }\end{array}$ & $A_{C}, R_{h}$ & $\begin{array}{l}\text { Merkli and thoinalun } \\
1975 \text {, Rapipritan } \\
\text { and Tu } 1980\end{array}$ \\
\hline lepyersal lephyth & $\begin{array}{l}\text { Aunnunt of time a flow } \\
\text { particle spends in } \\
\text { reggenerator }\end{array}$ & $\begin{array}{l}\text { Need to take time- } \\
\text { dependent effects } \\
\text { such ds variahle flow } \\
\text { profiles inta account }\end{array}$ & $\frac{A D}{E}$ & $\begin{array}{l}\text { Seume and Simon } \\
1986\end{array}$ \\
\hline \multicolumn{5}{|c|}{ Steep Tenperdure Gradient in FIm Direct ton } \\
\hline & $\begin{array}{l}\text { Varying flufd properties, } \\
\text { demsity and velocity along } \\
\text { reyenerator. Possible } \\
\text { eftects on flow structure }\end{array}$ & $\begin{array}{l}\text { Effects on transport } \\
\text { properties of fluld }\end{array}$ & & \\
\hline \multicolumn{5}{|l|}{ Prossure 0sci1lation } \\
\hline & $\begin{array}{l}\text { Compression heating, expan- } \\
\text { sisn conling. Possible } \\
\text { internal invelopment of } \\
\text { radial temperature gradients } \\
\text { within gas }\end{array}$ & $\begin{array}{l}\text { Effects on thermal } \\
\text { gradients /boundary } \\
\text { layers. Ef fect of } \\
\text { compressfng nonworking } \\
\text { gas, heat transfer to } \\
\text { nonworking gas }\end{array}$ & $\begin{array}{l}\frac{U^{2}}{\Delta T_{0} C_{p}} \\
C_{p} / C_{y}\end{array}$ & $\begin{array}{l}\text { Schllehting } 1979 \\
\text { Faulkner and sinith } \\
1983 \\
\text { Wofs et al. } 19356\end{array}$ \\
\hline \multicolumn{5}{|c|}{ Flow Nonuniformity in Matrix } \\
\hline Wall Efferts & $\begin{array}{l}\text { Thin momentum and thermal } \\
\text { houndary layers on outer } \\
\text { wallis }\end{array}$ & $\begin{array}{l}\text { Significant hent transfer } \\
\text { effects } \leftrightarrow \text { outer walls }\end{array}$ & $\frac{P r}{u} \cdot \frac{G R e}{v^{2} L}$ & $\begin{array}{l}\text { Wafat and Tien } \\
1981\end{array}$ \\
\hline $\begin{array}{l}\text { Variable Porostiy } \\
\text { Media }\end{array}$ & $\begin{array}{l}\text { Increased flow through } \\
\text { part if matrix, often } \\
\text { near wall }\end{array}$ & $\begin{array}{l}\text { Increased heat transfer. } \\
\text { pressure drop losses }\end{array}$ & $\frac{L}{d_{p}}, \operatorname{Re}, \frac{L d}{K_{e}}$ & $\begin{array}{l}\text { Vafai, Alkire and } \\
\text { Tien ig85 }\end{array}$ \\
\hline $\begin{array}{l}\text { Nomistiform } \\
\text { Fntering Flnw }\end{array}$ & $\begin{array}{l}\text { Incrinsinf flow throught } \\
\text { part of matrix }\end{array}$ & $\begin{array}{l}\text { Increased heat transfer } \\
\text { pressure drop losses }\end{array}$ & & Gedeon 1915 \\
\hline \multicolumn{5}{|l|}{ Matrix Properties } \\
\hline Microstructure & $\begin{array}{l}\text { Metails of flow gemetry } \\
\text { determine flow structure. } \\
\text { transition to turbulence }\end{array}$ & $\begin{array}{l}\text { Affects all transport mech- } \\
\text { anisms affected by flow } \\
\text { structure, both friction } \\
\text { and heat iransfer }\end{array}$ & many & \\
\hline Material & $\begin{array}{l}\text { Heat capacity, surface, } \\
\text { properties, tntegrity, } \\
\text { corrnability }\end{array}$ & $\begin{array}{l}\text { Heat capacity detemines } \\
\text { thermodynamics in regen- } \\
\text { erator. Surface proper- } \\
\text { thes affect flow structure } \\
\text { and thus. friction and heat } \\
\text { transfer. }\end{array}$ & $\frac{c_{p} \text { matrix }}{c_{p} \text { Inota }}$ & Jones $1982 a$ \\
\hline
\end{tabular}




\section{TABLE A.2. Documented Engines}

\begin{tabular}{|c|c|c|c|c|}
\hline Engine Type & \multicolumn{2}{|c|}{ Operating Conditions } & \multirow[t]{2}{*}{ Purpose } & \multirow[t]{2}{*}{ Abbreviations } \\
\hline Kinematic Engines & & & & \\
\hline General Motors GPU-3 & $\begin{array}{l}\text { Speed or frequency: } \\
\text { Mean pressure: } \\
\text { Working fluid: }\end{array}$ & $\begin{array}{l}2500 \mathrm{rpm} \\
41 \mathrm{bar} \\
\text { He }\end{array}$ & $\begin{array}{l}\text { Test, power generation--power, } \\
\text { density, efficiency }\end{array}$ & GPU3 \\
\hline $\begin{array}{l}\text { Mechanical Technologies Inc. } \\
\text { M00I (upgraded) }\end{array}$ & $\begin{array}{r}\text { Speed or frequency: } \\
\text { Mean pressure: } \\
\text { Working fluid: }\end{array}$ & $\begin{array}{l}4000 \mathrm{rpm} \\
150 \mathrm{bar} \\
\mathrm{H}_{2}\end{array}$ & $\begin{array}{l}\text { Automotive--power, effictency, } \\
\text { emissions }\end{array}$ & MODI \\
\hline United Stifling 940 & $\begin{array}{l}\text { Speed or frequency: } \\
\text { Mean pressure: } \\
\text { Working fluid: }\end{array}$ & $\begin{array}{l}4000 \text { rpin } \\
150 \text { bar } \\
\mathrm{H}_{2}\end{array}$ & $\begin{array}{l}\text { Test, Automatic=-power, } \\
\text { efficiency, emissions, } \\
\text { modularity }\end{array}$ & $P 4 Q$ \\
\hline $\begin{array}{l}\text { Technical University of Denmark, } \\
\text { Stirling Total Energy System }\end{array}$ & $\begin{array}{r}\text { Speed or frequency: } \\
\text { Mean pressure: } \\
\text { Working fluid: }\end{array}$ & $\begin{array}{l}1500 \text { rpm } \\
100 \text { bar } \\
\text { He }\end{array}$ & $\begin{array}{l}\text { Cogeneration--efficiency, } \\
\text { reliability }\end{array}$ & STES \\
\hline $\begin{array}{l}\text { UK Consortium, Stirling Engine } \\
\text { (a configuration) }\end{array}$ & $\begin{array}{l}\text { Speed or frequency: } \\
\text { Mean pressure: } \\
\text { Working fluid: }\end{array}$ & $\begin{array}{l}3000 \mathrm{rpm} \\
150 \mathrm{bar} \\
\mathrm{He}\end{array}$ & $\begin{array}{l}\text { General Purpose Test -- } \\
\text { modularity }\end{array}$ & JK \\
\hline Ford Phillips 4-215 & $\begin{array}{l}\text { Speed or frequency: } \\
\text { Mean pressure: } \\
\text { Working fluid: }\end{array}$ & $\begin{array}{l}4000 \text { rpm } \\
103 \text { bar } \\
\mathrm{H}_{2}\end{array}$ & $\begin{array}{l}\text { Automative-power, efficiency, } \\
\text { emissions }\end{array}$ & $4-215$ \\
\hline General Motors $4 \mathrm{~L} 23$ & $\begin{array}{l}\text { Speed or frequency: } \\
\text { Hean pressure: } \\
\text { Working fluid: }\end{array}$ & $\begin{array}{l}2000 \mathrm{rpm} \\
103 \mathrm{bar} \\
\mathrm{H}_{2}\end{array}$ & $\begin{array}{l}\text { Automotive-power, efficiency, } \\
\text { emissions }\end{array}$ & $4 L 23$ \\
\hline Eree Piston Engines & & & & \\
\hline $\begin{array}{l}\text { Mechanical Technalogies Inc. } \\
\text { Engineering Model }\end{array}$ & $\begin{array}{r}\text { Speed or frequency: } \\
\text { Mean pressure: } \\
\text { Working fluid: }\end{array}$ & $\begin{array}{l}58 \mathrm{~Hz} \\
60 \mathrm{har} \\
\text { He }\end{array}$ & General Purpase Test & $E M$ \\
\hline $\begin{array}{l}\text { Sunpower Inc. } 3 \mathrm{~kW} \text { Generator } \\
\text { Set }\end{array}$ & $\begin{array}{l}\text { Speed or frequency: } \\
\text { Mean pressure: } \\
\text { Working fluid: }\end{array}$ & $\begin{array}{l}60 \mathrm{~Hz} \\
25 \mathrm{bar} \\
\mathrm{air}\end{array}$ & $\begin{array}{l}\text { Power Generation--efficiency, } \\
\text { reliability }\end{array}$ & Genset \\
\hline Sunpower Inc. RE-1000 & $\begin{array}{l}\text { Speed or frequency: } \\
\text { Mean pressure: } \\
\text { Working fluid: }\end{array}$ & $\begin{array}{l}30 \mathrm{~Hz} \\
70 \mathrm{bar} \\
\mathrm{He}\end{array}$ & $\begin{array}{l}\text { General Purpose Test-. } \\
\text { simplicity }\end{array}$ & RE1000 \\
\hline $\begin{array}{l}\text { Mechanical Technologies Inc. } \\
\text { Space Power Demonstrator } \\
\text { Engine }\end{array}$ & $\begin{array}{l}\text { Trial Parameters: } \\
\text { Speed or frequency: } \\
\text { Mean pressure: } \\
\text { Working fluid: } \\
\text { Deslgn Parameters: } \\
\text { Speed or frequency; } \\
\text { Mean pressure: } \\
\text { Working fluid: }\end{array}$ & $\begin{array}{l}73 \mathrm{~Hz} \\
75 \mathrm{bar} \\
\mathrm{He} \\
105 \mathrm{~Hz} \\
150 \mathrm{bar} \\
\mathrm{He}\end{array}$ & $\begin{array}{l}\text { Space Power--high power } \\
\text { density, light weight, } \\
\text { long life }\end{array}$ & SPDE-T \\
\hline
\end{tabular}

Source: Adapted from Seume and Simon, 1986. 
TABLE A.3. Data on Friction and Heat Transfer in Regenerators and Porous Media

Authors

Steady Fion

Littman, Bartle, and Pulsifer 1968

Gupta et al. $\$ 974$

Míabe, Takahashi and Hamaguch 1982

Chen and Griffin

1983

\section{Oscillating flow}

Murray and Martin 1961

Bartolini and Naso 1984

Rice et al. 1983

Rice, Thonger and Dadd 1985

Nakajima et al. 1985
Experiment

Frequency response heat transfer

Correlation of 17 studies of packedbed heat transfer

Steady flow friction

in stacked screens

Steady heat transfer in stacked screens

Recorrelation of Kays and London data on steady flow friction

Sinusoidai flow, heat transfer in wre mesh screens

Pertodic flow

Sinusoidal flow heat transfer-

calorimetric

approach reduced

to effectiveness

via reduced length

approach

Simusoldal fiow

heat transfer--

from finite element

caiculation and

measurement of

entrance and exit

temps.

Sinusoidal flow pressure drop in stacked screens
Correlation

Not given

$S \operatorname{tgr}^{2 / 3}=\frac{2.876}{\delta_{d}}+\frac{.3023}{8 \operatorname{Re}_{d}} \cdot 35$

$f \times \frac{33.6}{\operatorname{Re}_{p}}+.337$

$N u_{d}=.42 R e_{d} .56$

$f=\frac{49.78}{\operatorname{Re}_{1} .968}+.317$

None obtained

$h=.05 \frac{k}{r_{h}}(\mathrm{Pe})^{.75}$

$N u=.46 R_{e} .78$

Typical results are

Nup $=.04 R e 0$ for

200 mesh, $3.33 \mathrm{~Hz}$

$\mathrm{N}_{2}$ working fluid,

$\delta=.71$

$f=\frac{49.6}{\text { Re }}+.504$

Re 10-500, 100 and

200 mesh screens
Conments

Focus on low Reynolds number (based on particle diameters) data (2-100) dynamic thermal conductivity of solid phase measured; rises sharply for Re<6.

Reynolds number based on superfictal velocity and particle diameter (10 $-10,000)$

Hicroscopic approach; $\operatorname{Re}_{1}=1 \mathrm{u} / \mathrm{v}$. where ? is distance between wires in mesh, $u$ is fluid velocity within mat rix

$N_{d}=d_{m} h / k$, where $d_{m}$ is mesh wire diameter. $\mathrm{Re}_{d}$ is also based on mesh vire diameter.

$3<$ Re, < 2000; parameters same as Hiyabe et al. 1982

For given average Reynolds \#, heat transfer increases with porosity. High porosity matrices also respond to changes in frequency (range 25-

200) wile lower ones do not.

Where the Peclet number Pe $w u r_{h} / \alpha$ $r_{h}=4$ (cross-sect iond ared) perimeter

Mean Reynoids 6-100, varied by fncreasing gas pressure (helium) in

rig. Tested frequencies $6-11 \mathrm{~Hz}$. Re and Nu based on a hydraulic diameter, see Rice et al. 1985.

$0=$ Hydraulic diameter

$d_{m} \frac{2 \delta}{1+\delta}$

$R_{e}=\frac{u d_{m}}{v} \quad d_{m}$ is wire diameter

$f=\frac{2 \Delta P_{2}}{{ }^{2} n} \quad u=$ velocity in matrix

in regenerator 


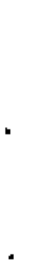


APPENDIX B

NOMENCL ATURE 
APPENDIX B

NOMENCLATURE

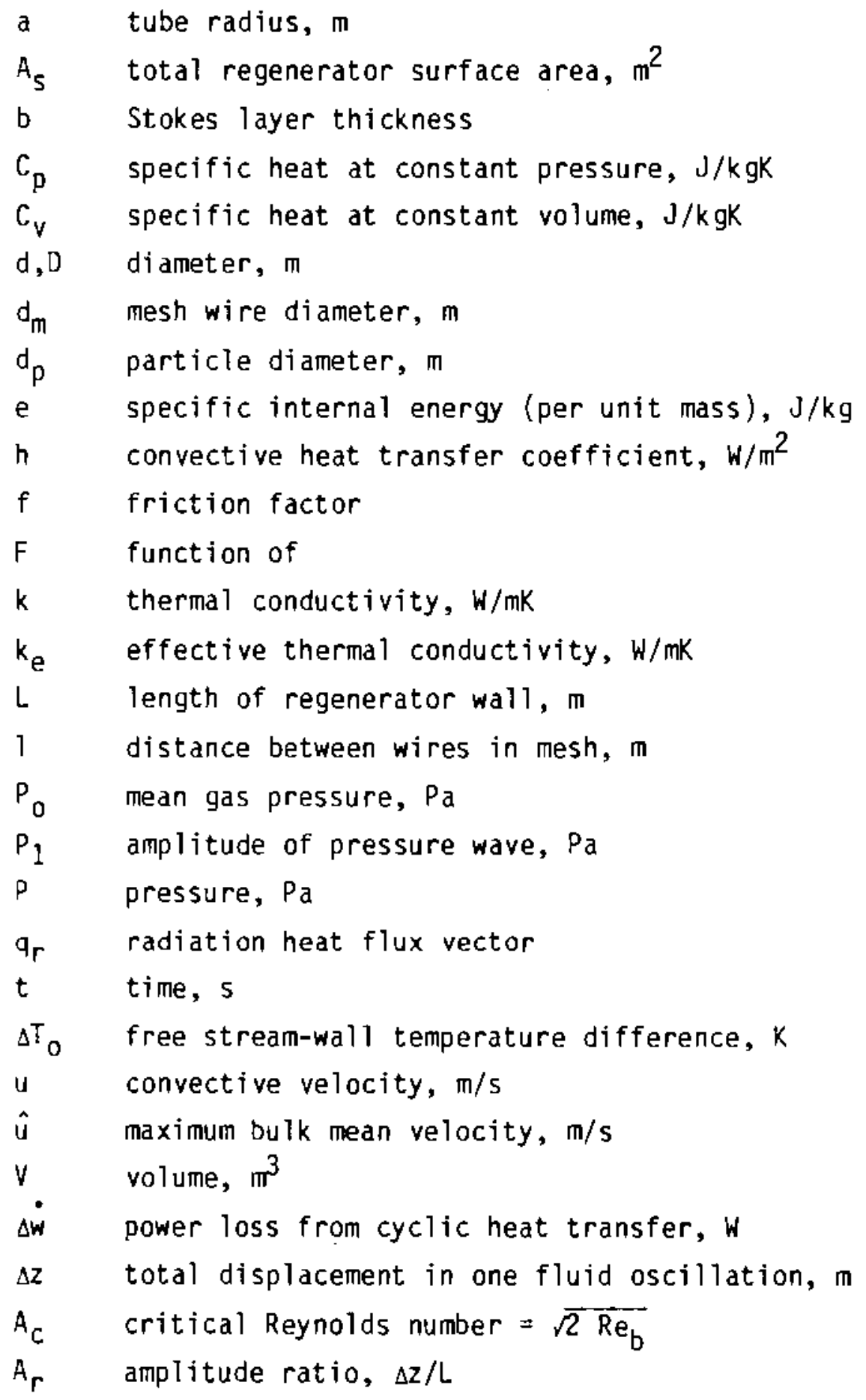


$E \quad$ Eckert number, $u^{2} / \Delta T_{0} C_{p}$

$G$ defined function for convective terms in flow through a porous medium, $F\left(K, \operatorname{Re}_{L}\right.$, Geometry) $\delta \bar{k}$

Nu Nusselt number

Pr Prandtl number

Re Reynolds number, based on regenerator length ( $L$ ), Stokes layer thickness (b), permeability $(k)$, maximum bulk mean velocity (max), as subscripted

Rew kinetic Reynolds number, $\omega d^{2} / 4 v$

St Stanton number

y nondimensional hydraulic radius, gap width $/ 2 \sqrt{2 \alpha / \omega}$

* thermal diffusivity, $\mathrm{m}^{2} / \mathrm{s}$

w radian frequency, $1 / \mathrm{s}$

$v \quad k$ kinematic viscosity, $\mathrm{m} / \mathrm{s}$

$\rho \quad$ density, $\mathrm{kg} / \mathrm{m}$

* permeability, $m^{2}$

$\delta$ porosity

$\epsilon$ ratio of peak mass velocity in oscillating flow to that in steady flow

$\mu \quad$ viscosity, $\mathrm{kg} / \mathrm{ms}$

- mechanical or viscous dissipation function

r $\quad \mathrm{C}_{\mathrm{p}} / \mathrm{C}_{\mathrm{v}}$

* dimensionless quantity

$+\quad$ vector 


\section{REFERENCES}

Barker, J. J. 1965. "Heat Transfer in Packed Beds." Industry and Engineering Chemistry (Industrial edition), $57(4): 43$.

Barnes, C., and G. T. Reader. 1986. "An Investigation Into the Effect of Various Regenerators on the Performance of a Stirling Engine." In Proceedings, 21st Intersociety Energy Conversion Engineering Conference IECEC, pp. 512. American Chemical Society, Washington, D.C.

Bartolini, C. M.. 1981. "L'impianto di prova per rigeneratori termici a regime peridico rapido." Paper presented at the XXXVI Congresso Nazionale A.T.I., Viareggio, Italy.

Bartolini, C. M., and V. Naso. 1984. "Parametric Thermal Analysis of the Stirling Engines Metal Regenerators." In Proceedings 19th IECEC, pp.2067. American Nuclear Society, La Grange Park, IL.

Bayley, F. J., and C. W. Rapley. 1961. "Performance of Thermal Regenerators Under Sinusoidal Flow Conditions, Part II." Paper presented at the ASME/ IMechE Heat Transfer Conference, American Society of Mechanical Engineers, New York.

Beavers, G. S., and E. M. Sparrow. 1969. "Non-Darey Flow Through Fibrous Porous Media." Journal of Applied Mechanics, 69-APM-CC.

Bolleta, D., et al. 1981. "Indagine sperimentale di rigeneratori termici per macchine a gas caldo." Graduation Thesis, University of Ancona.

Chen, N. J. C., and F. P. Griffin. 1983. "Effects of Pressure-Drop Correlations on Stirling Engine Predicted Performance." In Proceedings, 18th IECEC, pp. 708. American Institute of Chemical Engineers, New York.

Dadd, M. W. 1982. "Fast Response Thermometry in Stirling Engines." In Proceedings, 17th IECEC, p. 1875. Institute of Electrical and Electronic Engineers, New York.

Dijkstra, K. 1984. "Non Stationary Heat Transfer in Heat Exchangers." In Proceedings, 19th IECEC, p. 1886. American Nuclear 5ociety, La Grange Park, Illinois.

Dybbs, A., K. Kar, M. Groeneweg, J. K. Ling and M. Naraghi. 1984. A New Interpretation of Internal Heat Transfer Coefficients for Porous Media. ASME 84-WA/HT-5l, American Society of Mechanical Engineers, New York.

Faulkner, H. B., and J. C. Smith. 1983. "Instantaneous Meat Transfer During Compression and Expansion in Reciprocating Gas HandTing Machinery. "In Proceedings, 18th IECEC, pp. 724. American Institute of Chemical Engineers, New York. 
Finegold, J.G., and R. W. Sterrett. 1978. Stirling Engine Regenerators Literature Review. JPL \#5030-230, Jet Propuision Laboratory, Pasadena, California.

Galitseiskii, B. M., and A. N. Ushakov. 1982. "Heat Exchange in Porous Media." Journal of Engineering Physics, pp. 951. Translated from Inzhenerno-Fierchesski Zhurma 1, 41(3):428, 1981.

Galitseiskii, B. M., Y. A. Ryzhov and E. U. Yakush. 1977. "Thermal and Hydrodynamic Processes in 0scillating Flows (in Russian)." Mashinostroeme, Moscow.

Gedeon, D. 1985. "Computational Techniques for the Two-Dimensional Gasdynamic Equations in Stirling Engine Regenerators and associated Manifolds." In Pro-ceedings, 20th IECEC, p. 3.354. Society of Automotive Engineers, Warrendale, Pennsylvania.

Gedeon, D. 1986. "Mean-Parameter Modeling of Oscillating Flow." Journal of Heat Transfer, 108:513.

General Electric. 1984. Development and Demonstration of a Stirling/Rankine Heat Activated Heat Pump. ORNL/Sub/82-17485/1, Oak Ridge National Laboratory, Oak Ridge, Tennessee.

Gupta, S. N., et al. 1974. "Fluid-Particle Heat Transfer in Fixed and Fluidized Beds." Chemical Engineering Science, 29(3):839.

Hamaguchi, K., S. Takahashi and H. Miyabe. 1981a. "Heat Transfer Characteristics of Regenerator Matrix." Reprints of the Japanese Society of Mechanical Engineers (in Japanese), 810-12:69.

Hamaguchi, K., S. Takahashi and H. Miyabe. 1981b. "Flow Losses of Regenerator Matrix." Reprint of the JSME (in Japanese), 812-3:19.

Hino, M., M. Sawamoto and S. Takasu. 1976. "Experiments on Transition to Turbulence in an 0scillatory Pipe Flow." Journal of Fluid Mechanics, 75:193.

Hutchinson, R. A., and S. E. Lyke. 1987. "Microcomputer Analysis of Regenerative Heat Exchangers for Oscillating Flow." In Proceedings, 1987 ASME/JSME Thermal Engineering Conference, American Society of Mechanical Engineers, New York.

Jones, 3. D. 1982a. "A New Regenerator Theory." In Proceedings, 17th IECEC, pp. 1656. Institute of Electrical and Electronics Engineers, Inc., New York.

Jones, J. D. 1982b. "Thermodynamic Design of the Stirling Engine." PhD. Thesis, University of Reading, England.

Jones, J. D. 1985. "Flow Losses in Stirling Engine Heat Exchangers." In Proceedings, 20th IECEC, PP.3.366. Society of Aumotive Engineers, Warrendale, Pennsylvania. 
Kays, W. M., and A. L. London. 1984. Compact Heat Exchangers. McGraw-Hill, New York.

Kornhauser, A. A., and J. L. Smith. 1987. "A Comparison of Cylinder Heat Transfer Expressions Based on Prediction of Gas Spring Hysteresis Loss." In Proceedings, 1987 ASME Winter Annual Meeting. American Socjety of Mechanical Engineers, New York.

Krazinski, J. L., R. E. Holtz, K. L. Uherka and P. A. Lottes. 1986. "An Analysis of Pressure Drops Under Oscillating Flow Conditions." In Proceedings, 1986 IECEC, Pp. 519. American Chemical Society, Washington, $\overline{D . C}$.

Kurzweg, Q. H., and L. Zhao. 1984. "Heat Transfer by High Frequency Oscillations: A New Hydrodynamic Technique for Achieving Large Effective Thermal Conductivities." Physics of Fluids, 27(11):2624.

Kurzweg, U. H. 1985. "Enhanced Heat Conduction in Fluids Subjected to SinusoidaT Oscillations." Journal of Heat Transfer, 107:459.

Lazarides, Y. G., C. J. Rall is and D. B. Kilgour. 1984. "Analys is and Design of Regenerators for Stirling Cycle Machines." In Proceedings, 19th IECEC, pp. 2061. American Nuclear Society, La Grange Park, I11inois.

Lee, K. P. 1983. "A Simplistic Model of Cyclic Heat Transfer Phenomena in Closed Spaces." in Proceedings, 18th IECEC, PP. 72D. American Institute of Chemical Engineers, New York.

Littman, H., R. G. Barile and A. H. Pulsifer. 1968. "Gas-Particle Heat Transfer Coefficients in Packed Beds at Low Reynolds Numbers." Industrial and Engineering Chemistry, 7(4):554.

Martini, W. M. 1983. Stirling Engine Design Manual. DOE/NASA/3194-1, NASA Lewis Research Center, Cleveland, Ohio.

Merkli, P., and W. Thomann. 1975. "Transition to Turbulence in Oscillating Pipe Flow." Journal of Fluid Mechanics, 58:595.

Mitsuda, A., et al. 1985. "Stirling Engine Research and Development in Japan." In Proceedings, 20th IECEC, pp. 3163. Society of Automotive Engineers, Warrendale, Pennsylvania.

Miyabe, H., S. Takahashi and K. Hamaguchi. 1982. "An Approach to the Design of Stirling Engine Regenerator Matrix Using Packs of Wire Gauzes." In Proceedings, $17 \mathrm{th}$ IECEC. Institute of Electrical and Electronic Engineers, Inc., New York.

Moynihan, T., R. Berggren and G. Dochat. 1983. Free-Piston Stirling Engine Experimental Program: Part 2 - An Evaluation of Loss Mechanisms. ANL-CT-83-7 Part 2, Argonne National Laboratory, Argonne, I11inois. 
Murray, J. A., and B. W. Martin. 1961. "Performance of Thermal Regenerators Under Sinusoidal Flow Conditions, Part I." Paper presented at the ASME/IMechE Heat Transfer Conference, American Society of Mechanical Engineers, New York.

Nakajima, N., H. Kohno and A. Azetsu. 1985. "Development of a Multi-Purpose Stirling Engine Using Wood Fuel." In Proceedings, 20th IECEC, pp. 3.332. Society of Automotive Engineers, Warren, Pennsylvania.

Organ, A. J. 1975. "The Concept of "Critical Length Ratio" in Heat Exchangers for Stirling Cycle Machines." In Proceedings, l0th IECEC, pp. 1776. American Nuclear Society, La Grange Park, IITinois.

Ramaprian, B. R., and S. Tu. 1980. "An Experimental Study of Oscillatory Pipe Flow at Transitional Reynolds Numbers." Journal of Fluid Mechanics, 100:513.

Rea, S. N., and J. L. Smith, Jr. 1967. "The Influence of Pressure Cycling on Thermal Regenerators." Journal of Engineering for Industry, 89(3):563.

Rice, G., J. D. Jones, M. W. Dadd and J. C. T. Thonger. 1983. "U.K. Consortium Stirling Engine Regenerator Effectiveness and Heater Performance." In Proceedings, 18th IECEC, pp. 714. American Institute of Chemical Engineers, New York.

Rice, G., J.C. T. Thonger and M. W. Oadd. 1985, "Regenerator Effectiveness Measurements." In Proceedings, 20th IECEC, pp. 3.266. Society of Automotive Engineers, Warrendale, Pennsylvania.

Roach, P. D. 1986. Reversing Flow Test Facility Technical Report - March 1986. ANL-CT-86-1, Argonne National Laboratory, Argonne, I11inois.

Seume, J., and T. Simon. 1986. "Oscillating Flow in Stirling Engine Heat Exchangers." In Proceedings, 21st IECEC, pp. 533. American Chemical Society, Washington, D.C.

Scheidegger, A. E. 1974. The Physics of Flow Through Porous Media. University of Toronto Press, Toronto.

Schlichting, H. 1979. Boundary-Layer Theory. McGraw-Hi1l, New York.

Slaby, J. G. 1986. "Overview of the 1986 Free-Piston Stirling SP-100 Activities at the NASA Lewis Research Center." In Proceedings, 21st IECEC, pp. 420. American Chemical Society, Washington, D.C.

Stang, J. S. 1970. Some Contributions to the Techniques for Testing Compact Heat Exchanger Surfaces. Technical Report \#74, Department of Mechanical Engineering Stanford University, Stanford, California.

Taylor, D. R., and H. Aghili. 1984. "An Investigation of 0scillating Flow in Tubes." In Proceedings, 19th IECEC, pp. 2033. American Nuclear Society, La Grange Park, Illinois. 
Tien, C. L., and K. Vafai. 1979. "Statistica1 Bounds for Effective Thermal Conductivity of Microsphere and Fibrous Insulation." Prog. Ast. Aero., $65: 135$.

Urieli, I., and D. M. Berchowitz. 1984. Stirling Cycle Engine Analysis. Adam Hilger, Ltd., Bristol, England.

Vafai, K., and C. L. Tien. 1981. "Boundary and Inertia Effects on Flow and Heat Transfer in Porous Media." International Journal of Heat and Mass Transfer, $24: 195$.

Vafai, K. 1984. "Convective Flow and Heat Transfer in Variable-Porosity Media." Journal of Fluid Mechanics, 147:233.

Vafai, K., R. L. Alkire and C. L. Tien. 1985. "An Experimental Investigation of Heat Transfer in Variable Porosity Media." Journal of Heat Transfer, $107: 642$.

Walker, G., and V. Vasishta. 1970. "Heat Transfer and Flow Friction Characteristics of Dense-mesh Wirescreen Stirling-cycle Regenerators." In Advances in Cryogenic Engineering, Vol $16, p .302$. Plenum Press.

Wolfs, M. J. M., K. Dijkstra and H. de Jorge. 1986. "On The Determination of the Regenerator Losses in Stirling Cycles." In Proceedings, International Heat Transfer Conference. San Francisco, California. 


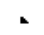

, 


\section{DISTRIBUTION}

No. of

Copies

OFFSITE

30 Technical Information Center

R. Abarcar

Energetics, Inc.

9210 Route 108

Columbia, MO 21045

R. A. Ackerman

MTI, Inc.

968 Albany-Shaker Road

Latham, NY 12110

W. Beale

Sunpower, Inc.

6 Byard Street

Athens, $\mathrm{OH} 45701$

D. Berchowitz

Sunpower, Inc.

6 Byard Street

Athens, OH 45701

D. Beremand

NASA Lewis Research Center

MS 301-2

21000 Brookpark Road

Cleveland, $\mathrm{OH} 44135$

J. J. Brogan

CE-12

U.S. Department of Energy

1000 Independence Avenue

Washington, DC 20585

F. C. Chen

Oak Ridge National Laboratory

P.0. Box Y

Oak Ridge, TN 37831
No. of

Copies

\section{A. Chesnes \\ CE-15}

U.S. Department of Energy

1000 Independence Avenue

Washington, DC 20585

M. H. Chiogioji

CE-15

U.S. Department of Energy

1000 Independence Avenue

Washington, OC 20585

J. Corey

MTI, InC.

968 Albany-Shaker Road

Latham, NY 12110

F. Creswick

Oak Ridge National Laboratory

P. O. BoX Y

Dak Ridge, TN 37831

J. E. Dudenhoefer

NASA Lewis Research Center

MS 301-2

21000 Brookpark Road

Cleveland, $\mathrm{OH} 44135$

A. Dybbs

Dept. of Mechanical and Aerospace Engineering

Case Western Reserve University

University Circle

Cleveland, $\mathrm{OH} 44106$

J. Eberhardt

CE -12

U.S. Department of Energy

1000 Independence Avenue

Washington, DC 20585

W. Ernst

MTI, Ine.

968 Albany-Shaker Road

Latham, NY 12110 
No. of

Copies

P. Fairchild

Oak Ridge National Laboratory

P.0. Box $Y$

Oak Ridge, TN 37831

R. Fiskum

CE -132

U.S. Department of Energy

1000 Independence Avenue

Washington, DC 20585

D. Gedeon

Gedeon Associates

Box 141A

South Canaan Road

Athens, $\mathrm{OH} 45701$

B. Goldwater

MTI, Inc.

968 Albany-Shaker Road

Latham, NY 12110

M. E. Gunn

$C E-12$

U.S. Department of Energy

1000 Independence Avenue

Washington, DC 20585

B. Holtz

Argonne National Lab

9700 S. Cass Avenue

Argonne, IL 60439

N. Isshiki

2-29-6 Kyoko

Setagayaxu, Tokyo 156

JAPAN

L. Johannson

Stirling Power Systems

7101 Jackson Road

Ann Arbor, MI 48103

A. L. London

Mechanical Engineering Dept.

Stanford University

Stanford, CA 94305
No. of

Copies

A. Maret

Gas Research Institute

8600 West Bryn Mawr Avenue

Chicago, IL 60631

J. P. Millhone

CE-13

U.S. Department of Energy

1000 Independence Avenue

Washington, DC 20585

N. Nightingale

MTI, Inc.

968 Albany-Shaker Road

Latham, NY 12110

A. J. Organ

University Engineering Department

Cambridge University

Trumpington Street

Cambridge, CB2 1PZ

ENGLAND

G. Reader

Royal Naval Engineering College

Manaden, Plymouth

ENGLAND

P. Riggle

Stiriing Technology Company

Richland, WA 99352

P. D. Roach

Argonne National Lab

9700 S. Cass Avenue

Argonne, IL 60439

J. D. Ryan

CE-132

U.S. Department of Energy 1000 Independence Avenue

Washington, DC 20585

J. Seume

Dept. of Mechanical Engineering 125 Mechanical Engineering Bldg.

111 Church Street S.E.

Minneapolis, MN 55455 
No. of

Copies

T. Simon

Dept. of Mechanical Engineering

125 Mechanical Engineering Bldg.

111 Church Street S.E.

Minneapolis, MN 55455

J. Slaby

NASA Lewis Research Center

MS 301-2

21000 Brookpark Road

Cleveland, $\mathrm{OH} 44135$

J. L. Smith, Jr.

Cryogenic Engineering Lab

Massachusetts Institute of

Technology

Cambridge, MA 02139

P. Sutton

CE -15

U.S. Department of Energy

1000 Independence Avenue

Washington, DC 20585

W. P. Teagan

A. D. LittTe, Inc.

Acorn Park

Cambridge, MA 02140

R. Tew

NASA Lewis Research Center

MS 301-2

21000 Brookpark Road

CTeveland, $\mathrm{OH} 44135$

D. Vaughn

U.S. Army BeTvoir R\&O Center

Fort Belvoir

Fairfax, VA 22060

G. Walker

Dept. of Mechanical Engineering

University of Calgary

Calgary, Alberta

CANAOA

C. D. West

Oak Ridge National Laboratory

P.0. Box $Y$

Oak Ridge, TN 37831
No. of

Copies

M. White

Stirling Technology Company

Richland, WA 99352

G. Wood

Route 1 Box 222

Albany, $\mathrm{OH} 45710$

B. Ziph

Stirling Thermal Motors, Inc. 2841 Boardwalk

Ann Arbor, MI 48104

ONSITE

DOE Richland Operations Office

J. J. Sutey

28 Pacific Northwest Laboratory

Z. Antoniak

W. B. Ashton

G. J. Hane

R. A. Hutchinson (15)

B. M. Johnson

B. A. Ross

C. M. Stewart

Publishing Coordination MH (2)

Technical Report Files (5) 
